\title{
Nitride-Based Materials for Flexible MEMS Tactile and Flow Sensors in Robotics
}

\author{
Claudio Abels ${ }^{1,2,3,+}$, Vincenzo Mariano Mastronardi ${ }^{1,+}$, Francesco Guido ${ }^{1}$, Tommaso Dattoma ${ }^{1}$, \\ Antonio Qualtieri ${ }^{1}$, William M. Megill ${ }^{3}$, Massimo De Vittorio ${ }^{1,2, *}$ and Francesco Rizzi ${ }^{1, *}$ \\ 1 Center for Biomolecular Nanotechnologies @UNILE, Istituto Italiano di Tecnologia (IIT), \\ Arnesano (LE) 73010, Italy; claudio.abels@hsrw.eu (C.A.); vincenzo.mastronardi@iit.it (V.M.M.); \\ francesco.guido@iit.it (F.G.); tommaso.dattoma@iit.it (T.D.); antonio.qualtieri@iit.it (A.Q.) \\ 2 Dipartimento di Ingegneria dell'Innovazione, Università del Salento, Lecce 73100, Italy \\ 3 Faculty of Technology and Bionics, Rhine-Waal University of Applied Sciences, Kleve 47533, Germany; \\ william.megill@hsrw.eu \\ * Correspondence: massimo.devittorio@iit.it (M.D.V.); francesco.rizzi@iit.it (F.R.); \\ Tel.: +39-0832-1816-244 (F.R.) \\ + These authors contributed equally to this work.
}

Academic Editor: Vittorio M. N. Passaro

Received: 14 March 2017; Accepted: 5 May 2017; Published: 10 May 2017

\begin{abstract}
The response to different force load ranges and actuation at low energies is of considerable interest for applications of compliant and flexible devices undergoing large deformations. We present a review of technological platforms based on nitride materials (aluminum nitride and silicon nitride) for the microfabrication of a class of flexible micro-electro-mechanical systems. The approach exploits the material stress differences among the constituent layers of nitride-based (AlN/Mo, $\mathrm{Si}_{x} \mathrm{~N}_{y} / \mathrm{Si}$ and AlN/polyimide) mechanical elements in order to create microstructures, such as upwardly-bent cantilever beams and bowed circular membranes. Piezoresistive properties of nichrome strain gauges and direct piezoelectric properties of aluminum nitride can be exploited for mechanical strain/stress detection. Applications in flow and tactile sensing for robotics are described.
\end{abstract}

Keywords: MEMS; stress-driven; aluminum nitride; silicon nitride; piezoelectric; piezoresistive; tactile sensing; flow sensing

\section{Introduction}

Inspired by nature, where biological sensors can adapt their mechanical sensitivity to cope with large changes in the environment, flexible functional materials can be used to tune and efficiently control how mechanical information can be detected and transferred in a biomimetic sensor design. Recent developments in thin-film-based MEMS have enabled the cost-effective manufacture of these flexible functional materials.

The sensing elements of the MEMS devices we review here typically consist of deformable flexural elements, such as cantilever beams, membranes and bridges, which are suspended above a base layer. These are usually designed and fabricated with silicon as the structural material [1,2]. Multiple additional layers are added to the base using appropriate deposition techniques in order to create a controllable stress gradient across the layered structure. On release (which has to be done carefully to avoid problems due to upper layers adhering to lower ones during the etching process [3]), the stress gradient creates "out-of-plane" architectures, such as upwards-bent cantilevers or dome-shaped membranes. This approach makes it possible to design mechanical devices that are sensitive to both normal and shear forces, widening the range of applications of flexible MEMS towards tactile, pressure and flow sensing in robotics. 
The flexural stiffness of the deformable elements has to be carefully designed and implemented by growth techniques in order to maximize the sensitivity of the sensor while ensuring it does not fail due to mechanical overloading. The micro-scale geometrical design made possible through modern MEMS manufacturing techniques provides the tool required to solve this apparent paradox. The thickness, width, length and curvature of the deformable element can all be determined quantitatively at design time, and the cavities left behind during the release process can provide shelter for the deformable element during periods of overload by distributing the force over the larger and stronger main substrate.

This review focuses on approaches to the design and fabrication of "stress-driven" flexible MEMS for sensing applications, providing an overview of some recent technological improvement in microfabrication of nitride-based devices (either aluminum nitride and silicon nitride) as a platform for developing a class of compliant and flexible MEMS undergoing and withstanding large deformations. In Section 2, we will introduce the materials science principles for obtaining nitride-based stress-driven microsystems. Section 3 describes the microfabrication methods for two different classes of stress-driven MEMS structures, i.e., piezoresistive upwards-bent cantilever beams and piezoelectric bowed circular membranes. In Section 4, results and application examples of bio-inspired piezoelectric tactile and piezoresistive flow sensors will be presented. Finally, conclusions are drawn in Section 5.

\section{Materials}

The realization of a stress-driven design requires a careful choice of material characteristics and an appropriate technology for material deposition. The proper choice of mechanical properties (shear modulus $G$, Young's modulus $E$ and Poisson ratio $v$ ) and suitable design parameters (thickness $t$ ) can be combined to design a specific flexural stiffness for flexible MEMS elements such as membranes and beams. Embedding and overlaying thin films with different thermal and elastic properties generates internal mechanical stresses. These forces are caused by multiple factors. The mismatch of atomic sizes in the different materials or the lattice-mismatch due to thermal treatments during material deposition and device microfabrication cause an intrinsic stress, which is usually considered detrimental to MEMS purposes, as it often causes failure due to surface wrinkles [4] or to buckle-delamination $[5,6]$ in compressive loading, or to channel cracks, which often appear in tensile loading [6]. In the "stress-driven" design approach, however, this phenomenon is instead directly exploited as an intrinsic release mechanism, which projects the suspended parts (beams and membranes) from the plane into the overlaying space.

Previous approaches to this design were based on a single layer structural element, such as a single silicon nitride layer grown by chemical vapor deposition (CVD) [7], polycrystalline silicon [8] and silicon dioxide [9]. The designed structural elements were affected by a stress gradient along their thickness, induced during their growth process. These approaches were characterized by a residual stress value, strongly related to the deposition technologies exploited to grow the single layer, and were difficult to replicate. As a consequence, it was hard to control the intrinsic stress conditions of the whole structure. A step forward came when the stressed structural element was designed as a multilayer structure. The stress control in the bent structure was obtained by carefully engineering the material stress difference among each multilayer component [10]. It was the relative difference among the internal stresses of different layers grown by CVD or epitaxial growth on a sacrificial layer that generated the required gradient in the stress profile through the multilayer thickness. If a tensile stress difference were realized in the multilayer, a controllable and repeatable upwards-bent mechanical structure could be obtained by detachment from a sacrificial or flexible layer via wet etching the layer underneath the structure away (e.g., cantilever beam fabrication), or by defining the mechanical element via adhesion detachment by stress relaxation (e.g., dome fabrication) [3]. 
The approach described above has been realized by exploiting nitride-based materials, such as Silicon Nitride (SiN) and Aluminum Nitride (AlN), whose intrinsic stress can be controlled via physical sputtering deposition or Low Pressure Chemical Vapor Deposition (LPCVD).

\subsection{Silicon Nitride Stressor Layer}

The careful control of silicon nitride residual stress has been studied since 1985, when Claassen et al. [11] studied the influence of the temperature, gas pressure and composition of silicon nitride thin films deposited on silicon substrates. Their findings were based on the observation of a temperature-dependent residual stress in the deposited film, ranging between tensile at high temperatures and compressive at low temperatures. More recent work has since been published on stress control of silicon nitride layers [12,13]. Silicon nitride-coated Silicon-On-Insulator (SOI) substrates are now the preferential template choice for silicon-based MEMS fabrication. This template consists of a $2 \mu \mathrm{m}$-thick silicon (device) layer on a $2 \mu \mathrm{m}$-thick Silicon dioxide $\left(\mathrm{SiO}_{2}\right)$ layer. Both layers are placed on a silicon substrate with a Miller index of (100). This template is obtained by depositing a thermal $\mathrm{SiO}_{2}$ layer on a silicon substrate, followed by bonding the $\mathrm{SiO}_{2}$ side on another silicon substrate. The SOI substrate is completed by mechanical thinning of one of the two bonded silicon substrates to $2 \mu \mathrm{m}$. Finally, a stoichiometric Silicon Nitride $\left(\mathrm{Si}_{3} \mathrm{~N}_{4}\right)$ layer is grown by LPCVD on both sides of the SOI substrate. This layer has an intrinsic tensile stress of $800 \mathrm{MPa}$, developed during the thermal cycling connected with the deposition, and is enough to generate a stress-difference in a Si $/ \mathrm{Si}_{3} \mathrm{~N}_{4}$ bi-layered beam. For a beam length of $1500 \mu \mathrm{m}$, this stress value generates an upwards bending up to $1200 \mu \mathrm{m}$ [14]. The placement of a piezoresistive strain gauge on the most stressed part of these mechanical elements, realized by deposition of metallic resistances or ion implantation, allows these devices to measure mechanical strain caused by fluid flow and shear forces $[7,10,15]$.

\subsection{Aluminum Nitride Stressor Layer}

Aluminum nitride thin films can be grown by sputtering with excellent polycrystalline quality on different substrates including dielectrics, semiconductors and metallic layers, as well as on flexible substrates, such as polymers and polyimides [16-24]. Due to its good electromechanical properties and low temperature growth technique (below $400^{\circ} \mathrm{C}$ ) in the sputtering chamber, AlN is suitable for the fabrication of stress-driven MEMS devices [25]. Previous studies faced the problem to control the built-in stress and the piezoelectric properties of AlN thin films deposited by reactive magnetron sputtering $[16,17,22]$. It was found that stress and piezoelectricity were very much dependent on the growth conditions (e.g., pressure, gas compositions, flow rates, bias voltage and underlying layers). Dubois et al. [16] investigated aluminum nitride thin films on polycrystalline metal electrodes. The typical columnar microstructure was obtained at a substrate temperature of $400{ }^{\circ} \mathrm{C}$ without correlation with the crystalline mismatch between AlN and the electrode. In parallel, the internal stress was found to be insensitive to the electrode material, but strongly dependent on the sputtering parameters and in particular to ion energy bombardment, which was able to generate step transitions from a tensile state to a compressive state. In contrast, the piezoelectric properties were found dependent on both electrode material and sputtering conditions. For example, platinum electrodes yielded better piezoelectricity values than aluminum and titanium, while particles deposited on the electrode were found to bear a certain amount of energy to generate a film with a high piezoelectric constant $\left(\mathrm{d}_{33}\right)$. Therefore, a trade-off between piezoelectricity, residual stress and crystalline quality of aluminum nitride should be found in order to increase the electromechanical coupling factor. Iborra and coworkers [17] found out that it was possible to control the negative effects of ionic bombardment (residual stress in first instance) by increasing the processing pressure in order to generate a more superficial interaction of ions with the growing surface and to obtain the worthwhile c-axis orientation and the columnar structure with a high value of the electromechanical coupling factor. Finally, a study of Jackson et al. [22] focused on the role of lattice mismatch with the substrate, validating the hypothesis that its reduction resulted in higher quality of AlN, regardless on which metal electrode aluminum nitride was deposited. 
In summary, a careful control of the energy supplied to ions allows for growing a pure c-axis orientation with a good piezoelectric response. Moreover, stress could range from strong compression to high tension by controlling the crystal mismatch between the underlying growth substrates.

In dependence of which stress-driven-based mechanical element will be fabricated, a proper substrate needs to be chosen. In order to obtain the control of residual stress in a cantilever structure, a silicon dioxide/silicon template can be used. Flexible beam fabrication was demonstrated on a silicon template made up of a $200 \mathrm{~nm}$-thick silicon dioxide layer, which is thermally grown on a (100) silicon substrate [26]. A $600 \mathrm{~nm}$-thick AlN layer upon a $100 \mathrm{~nm}$-thick Molybdenum (Mo) layer is grown by DC magnetron sputtering. For a $200 \mu \mathrm{m}$-long AlN/Mo beam, this stress gradient generates a tip height of approximately $150 \mu \mathrm{m}$ [26]. Control of AlN residual stress by sputtering was obtained on polyimide [19], commercial photoresist SU-8 (MicroChem Corp., Westborough, MA, USA) [24] and parylene [23] flexible and soft substrates for flexible mechanical elements. For dome fabrication, a $25 \mu \mathrm{m}$-thick polyimide layer is laminated on a silicon substrate, and subsequently, a sputtering growth process follows with the deposition of $120 \mathrm{~nm}$-thick Mo followed by an 800-1000 nm-thick AlN layer. In an analogous manner, AlN/Mo-based multilayers grown on a flexible polyimide substrate release tensile stress by an upward deflection reaching approximately $40 \mu \mathrm{m}$ for a diameter of $350 \mu \mathrm{m}$ [27]. Consequently, structural elements based on AlN/Mo or Mo/AlN/Mo multilayers can be used for bent structures, such as beams and membranes [26-28].

\subsection{Piezoelectric Properties of Aluminum Nitride}

The piezoelectric properties of aluminum nitride transform mechanical bending (as the response of the structure to external forces) into electrical signals, turning the bent structure into an efficient transducer. AlN possesses a number of key characteristics that make it very attractive when compared to other piezoelectric materials. $\mathrm{ZnO}$ and lead zirconate titanate (PZT) are well-known piezoelectric materials, which are limited in their application by the complexity and compatibility of their fabrication process (contamination risks in standard CMOS lines). Organic polymers such as Polyvinylidene Fluoride (PVDF) and its copolymer Poly(Vinylidene Fluoride-co-Trifluoroethylene) (P(VDF-TrFE)) have been widely used as tactile sensor piezoelectric materials [29-31]. PVDF is tough, extremely flexible, has a fast dynamic response and is readily available in the form of thin films [32]. PVDF is however difficult to involve in conventional microfabrication processes as it needs mechanical stretching to achieve the piezoelectric polar $\beta$-phase and high voltage poling to force the alignment of the internal dipoles.

Poly-crystalline inorganic aluminum nitride thin films can be obtained and easily deposited by reactive sputtering at relatively low temperature (from $160^{\circ} \mathrm{C}$ up to $250-300^{\circ} \mathrm{C}$ ) $[19,33]$ and directly grown with a very high degree of crystallinity even on plastic and flexible polymeric substrates, as polyimide. Moreover, it does not require poling or post-annealing procedures (as for PZT and PVDF) to exhibit and enhance its piezoelectric properties, since it is not a ferroelectric material. The high chemical stability of AlN allows it to be used in humid environments. Its high melting point allows AlN to withstand harsh environments, including temperatures above $500^{\circ} \mathrm{C}$, and its mechanical properties allow it to withstand high pressures. In spite of its piezoelectric coefficients, which are lower than other piezoelectric thin films $\left(\mathrm{d}_{33} \approx 4.9 \mathrm{pC} \mathrm{N}^{-1}\right.$ and $\left.\mathrm{d}_{31} \approx-1.9 \mathrm{pCN}^{-1}\right)$, it has a low dielectric constant $\left(\epsilon_{r} \approx 9-11\right)$ and low dielectric losses as a consequence, which results in an improved electromechanical coupling coefficient. Furthermore, AlN does not introduce contaminants into the CMOS micro-technology process, making it completely compatible with standard microfabrication technologies. It is also a nontoxic and, hence, highly bio-compatible material, as demonstrated by Jackson et al. [34]. Finally, the possibility to deposit extremely thin and flexible films of AlN on polymeric substrate together with very good electromechanical properties makes this material an excellent choice for the development of flexible tactile sensors. The strain gradient due to the bending of stress-driven structures and the resulting flexoelectric effect (the property of some dielectric solids to exhibit a linear relationship between the spontaneous electrical polarization and the gradient of 
mechanical strain) in non-ferroelectric aluminum nitride are responsible for an additional polarization, leading to an enhancement of the transduction properties of the material [35,36].

The integration of flexible polyimide with AlN thin film deposited by sputtering techniques has made possible the development of a wide range of flexible and compliant devices, from piezoelectric tactile sensors to piezoelectric micromachined Ultrasonic Transducers (pMUTs) and micro power generators, all based on stress differences between the constituent layers. By exploiting the quasi-unavoidable mechanical stress in these films due to the lattice mismatch and difference in thermal expansion coefficients of film and substrate, the sensory performance of structures such as upwards-bent cantilever beams and domed circular membranes can be improved.

\section{Methods}

This section describes the microfabrication process of two different classes of stress-driven MEMS structures, namely piezoresistive upwards-bent cantilever beams and piezoelectric tactile membranes.

\subsection{Microfabrication of Piezoresistive Upwards-Bent Cantilever Beams}

In the past, different stressor layers were micromachined on a silicon or silicon-on-insulator wafer, which provided the required residual stress to shape cantilevers that bent out of the plane after releasing, such as silicon nitride $[7,10,15]$, silicon dioxide $[9,37]$ and an aluminum nitride/molybdenum multilayer [26].

In this section, we review the processes used to fabricate these three stressor layers $\left(\mathrm{SiN}, \mathrm{SiO}_{2}\right.$, AlN/Mo). Their manufacture can be subdivided into four main stages, namely: (1) depositing functional material layers to induce the required residual stress; (2) depositing piezoresistors and contact pads; (3) defining the cantilever shape; and (4) releasing the cantilever.

Figure 1 gives an overview of the back-side bulk micromachining fabrication process for the MEMS-based air flow sensor described by Wang et al. [7]. Residual stress, released during the thermal fabrication process, was used to create a freestanding micro-cantilever beam, which used a platinum piezoresistor as the actual sensing element. Their fabrication process started with a low-pressure chemical vapor deposition of a $1 \mu \mathrm{m}$ low-stress silicon nitride layer on either side of a silicon wafer $(500 \mu \mathrm{m})$. In a subsequent electron-beam evaporation process, a thin chromium adhesion layer $(20 \mathrm{~nm})$ was deposited on the nitride layer. A second electron-beam evaporation process deposited the piezoresistor, a $100 \mathrm{~nm}$ platinum layer. Following the same deposition technique, a chromium adhesion $(20 \mathrm{~nm})$ and gold layer $(400 \mathrm{~nm})$ was deposited on top of the platinum layer to manufacture contact pads, the required electrical interface between the piezoresistor and an external resistance meter. Patterning the upper and lower nitride layers using Sulfur Hexafluoride (SF6) Reactive Ion Etching (RIE) plasma and, finally, releasing the cantilever structure by performing a potassium Hydroxide $(\mathrm{KOH})$ back-etching process at $80^{\circ} \mathrm{C}$, caused the cantilever structure to bend upward. By repeating the described MEMS procedure, but using different photomasks and layer thicknesses, Wang et al. [15] reassembled the air flow sensor with four cantilever beams positioned perpendicular to each other.

Zhang et al. [9] developed a top-side bulk micromachining releasing method using isotropic RIE to fabricate bent cantilevers on SOI wafers. The fabrication process was reported in detail by previous authors $[9,37]$ and is introduced briefly here. Instead of using a nitride-based stressor layer as described by [7], their approach is based on two silicon dioxide layers deposited by using two different deposition techniques and temperatures, as shown in Figure 2. While the first $400 \mathrm{~nm}$-thick Buried silicon dioxide (BOX) layer was fabricated using thermal oxidation at high temperatures above $1000^{\circ} \mathrm{C}$, the second silicon dioxide layer $(200 \mathrm{~nm})$ was deposited by Plasma-Enhanced Chemical Vapor Deposition (PECVD) at a low temperature of $300{ }^{\circ} \mathrm{C}$. This temperature difference generated different residual stresses in the two silicon dioxide layers, which in turn curved the cantilever upwards after its release. The piezoresistor was sandwiched between the two silicon dioxide layers. Similar to the nitride-based process [7] cited earlier, the residual stress in the silicon dioxide-based 
process is very sensitive to deposition parameters and requires an elaborate operation of the MEMS manufacturing process.
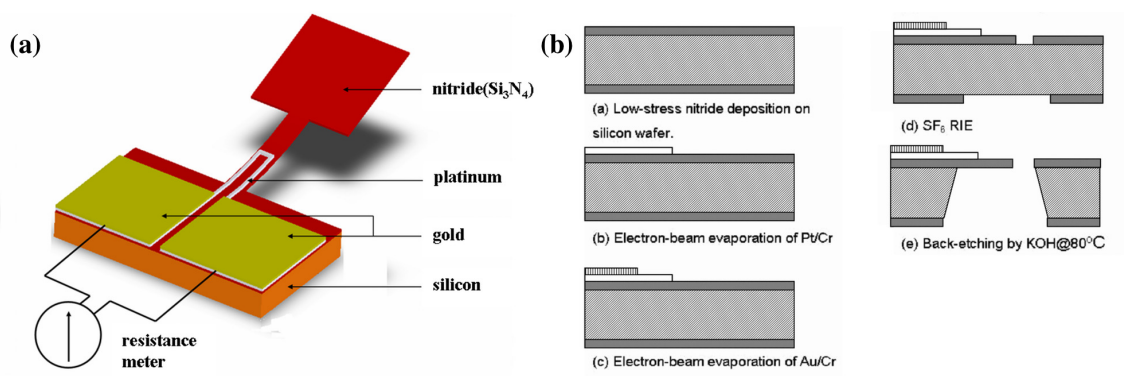

Figure 1. A MEMS-based air flow sensor with a free-standing micro-cantilever structure. (a) Schematic illustration and (b) overview of fabrication process employed for a gas flow sensor. Reproduced from Wang et al. [7].

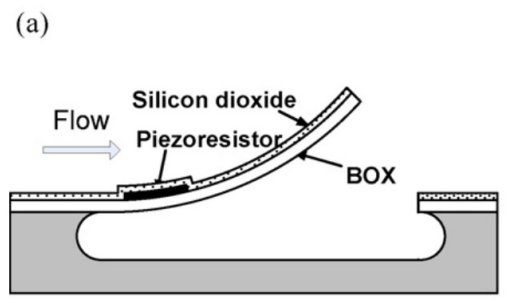

(b)

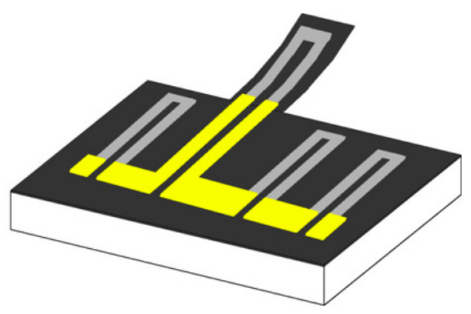

Figure 2. Self-bended silicon dioxide piezoresistive microcantilever flow sensor. (a) Cross-sectional and (b) perspective view. The highlight in (b) represents the metal interconnects. Reproduced from Zhang et al. [9] with permission of Elsevier B.V.

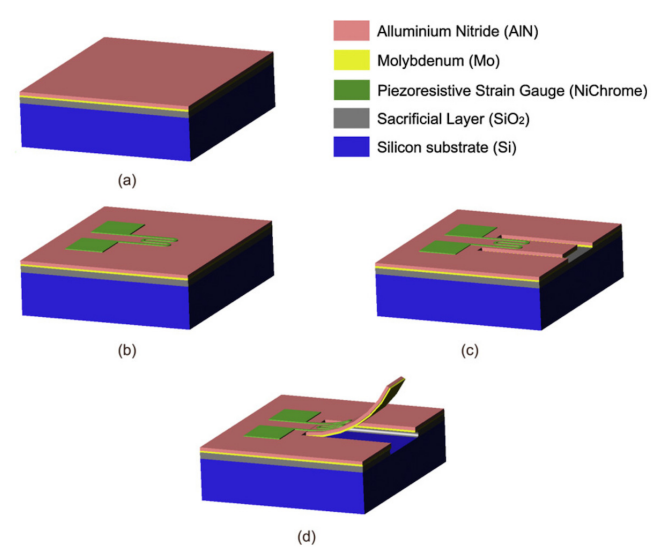

Figure 3. The MEMS fabrication process for an aluminum nitride/molybdenum based flow sensor. The process is subdivided into four main steps, that is (a) depositing functional material layers; (b) depositing piezoresistors and contact pads (thermal evaporation); (c) defining the cantilever U-shape (dry etching); and (d) releasing the cantilever (wet etching). Reproduced from Qualtieri et al. [26] with permission of Elsevier B.V.

Qualtieri et al. [26] described a surface micromachining fabrication process for AlN/Mo-based stress-driven micro-cantilevers, as illustrated in Figure 3. To induce residual stress, the top side of a silicon wafer ( $400 \mu \mathrm{m}$ thickness) was coated with $200 \mathrm{~nm}$ silicon dioxide, $100 \mathrm{~nm}$ molybdenum and 
$600 \mathrm{~nm}$ aluminum nitride. A nichrome 80/20 (80\% nickel, 20\% chrome) piezoresistor (100 nm) was deposited using physical thermal evaporation. To improve adhesion, $10 \mathrm{~nm}$ chrome was deposited between the AlN layer and the piezoresistor. A third deposition process layered two $150 \mathrm{~nm}$-thick gold contact pads. As before, $10 \mathrm{~nm}$ chrome between the nichrome and gold layer improved surface adhesion. To generate the U-shaped release pattern for the cantilever beam, Silicon tetrachloride $\left(\mathrm{SiCl}_{4}\right)$-based Inductively-Coupled Plasma (ICP) dry etching at the substrate top side patterned the first two layers and finished at the $\mathrm{SiO}_{2}$ layer. Designed as a sacrificial layer, the $\mathrm{SiO}_{2}$ layer beneath the cantilever beam was removed by isotropic wet etching in a hydrofluoric acid solution. Caused by the residual stress in the material, the released AlN/Mo bilayer bent out of the plane after the releasing process.

Adapted from their AlN/Mo flow sensor, Qualtieri et al. [38] developed a second bulk micromachining process for a SiN/Si-based stress-driven microcantilever, as shown in Figure 4. An SOI substrate, made up of a $400 \mu \mathrm{m}$ silicon wafer, a $2 \mu \mathrm{m}$-thick $\mathrm{SiO}_{2}$ insulation layer and a $2 \mu \mathrm{m}$ silicon device layer, was coated with $300 \mathrm{~nm} \mathrm{SiN} \mathrm{on} \mathrm{the} \mathrm{bottom} \mathrm{and} \mathrm{top} \mathrm{sides.} \mathrm{Four} \mathrm{nichrome} \mathrm{80/20}$ piezoresistors (100 nm thick), distributed along the full length of the cantilever beam and arranged electrically into a Wheatstone-bridge circuit, were deposited using a physical thermal evaporation. To improve adhesion, $10 \mathrm{~nm}$ chrome was deposited between the SiN layer and the piezoresistors. A third deposition process layered four gold contact pads $(150 \mathrm{~nm})$ onto the nichrome layer with $10 \mathrm{~nm}$ chrome in between to improve adhesion. $\mathrm{SiCl}_{4}$-based ICP dry etching at the top side SiN layer was performed to generate the U-shaped release pattern for the cantilever. A second ICP etching process of the bottom side SiN layer was performed to open an aperture to the silicon substrate underneath the cantilever beam. Subsequently, anisotropic back side wet etching with a $28 \% \mathrm{KOH}$ solution at $85^{\circ} \mathrm{C}$ created a cavity beneath the cantilever beam. The $\mathrm{SiO}_{2}$ insulating layer acted as an etching barrier. Next, hydrofluoric acid back side wet etching removed the $\mathrm{SiO}_{2}$ layer. By performing a last $\mathrm{KOH}$ top side wet etching, the exposed (U-shaped) silicon layer around the cantilever was removed. Caused by the residual stress in the material, the released SiN/Si bilayer bent out of the plane after releasing. After bonding wires to the contact pads, a waterproof parylene coating by chemical vapor deposition was performed, which added a conformal $2 \mu \mathrm{m}$ cover layer to all sides of the flow sensor (including the cantilever beam).

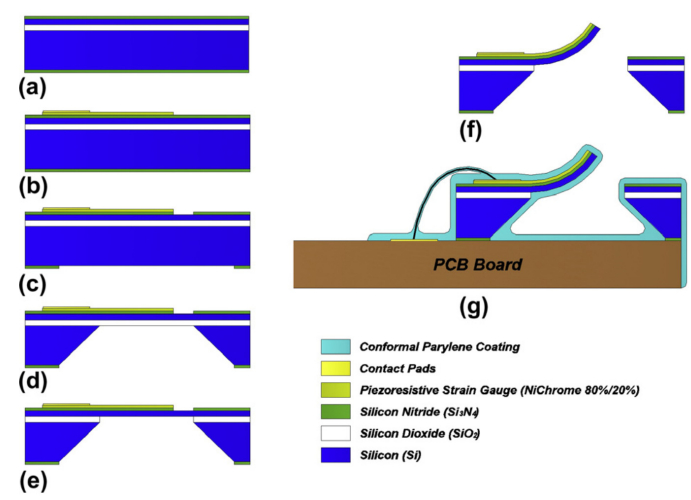

Figure 4. The MEMS fabrication process for a silicon nitride/silicon-based flow sensor. The process is subdivided into five main steps, that is: (a) depositing functional material layers; (b) depositing piezoresistors and contact pads (thermal evaporation); (c) defining the cantilever U-shape (dry etching); (d-f) releasing the cantilever (wet etching); and (g) waterproofing the sensor (chemical vapor deposition). Reproduced from Qualtieri et al. [38] with permission of Elsevier B.V.

\subsection{Microfabrication of Piezoelectric Tactile Membranes}

In the past, the main microfabrication techniques for piezoelectric tactile sensors did not use any stress-driven building approach. The most commonly adopted designs for the realization of 
piezoelectric tactile sensors involved flat mechanical structures as pressure sensitive elements, typically sandwiched between electrodes [31,39]. Bump structures, usually made of silicone or soft materials like rubber, were then attached to the top of the piezoelectric elements to transfer the contact forces to the sensitive element.

An array of square flat elements of PZT, formed by sol-gel techniques with a thickness of $\approx 400 \mathrm{~nm}$, fabricated on a thin elastomer substrate of silicone (thickness of $3.6 \mu \mathrm{m}$ ), were developed by Dagdeviren et al. [39] (as shown in Figure 13). Platinum electrodes were used to connect the PZT elements. Similarly, pressure sensors in the form of segmental arrays of parallel flat plate structures were fabricated by Khan et al. [31] sandwiching the piezoelectric P(VDF-TrFE) film between two printed metal layers of silver. Each module consisted of a $4 \times 4$ sensor array with a sensitive area of about $1 \times 1 \mathrm{~mm}^{2}$. The sensitivity of the final sensor was mostly determined by the piezoelectric properties of the material $[33,40,41]$.

Feng et al. [42] proposed the development of piezoelectric Dome-Shaped-Diaphragm Transducers (DSDTs) because 3D structures are able to achieve higher sensitivity than their planar counterparts by concentrating the applied pressure at the center of the piezoelectric curved cell. Afterwards $\mathrm{Li}$ et al. [29] realized this innovative 3D dome-shape $\mathrm{P}(\mathrm{VDF}-\mathrm{TrFE})$ tactile sensor using a mold-transfer method from a cyclic-olifen-copolymer (COC) lens mold and standard MEMS techniques. To maintain the shape of the final sensor, the cavity of the domes was filled with implantable-grade silicone adhesive. Kim et al. [30] also demonstrated that a dome-shaped piezoelectric tactile sensor fabricated by an inflation technique can achieve higher sensitivity than the conventional flat structures. They conceptually fabricated the final sensor by trapping and inflating the air by means of a pre-polarized film of PVDF, a glass wafer and a face structure. A silver electrode layer (thickness $=10 \mu \mathrm{m}$ ) was deposited on a PVDF film by screen printing. Then, $250 \mu \mathrm{m}$-thick SU-8 structures were patterned on a glass wafer and used for local deformation of the PVDF film once the film is attached on the glass substrate. Through subsequent heat treatments, allowing the PVDF film to change shape, air was inflated and trapped underneath the locally deformed PVDF regions to achieve the desired dome geometry. The PVDF film was then released from the glass wafer. Finally, the PVDF film was turned upside down, and the back electrode layer was deposited by screen printing. Figure 5 displays the schematic illustration and the fabrication steps for the dome-shaped tactile sensors described by Kim et al. [30].
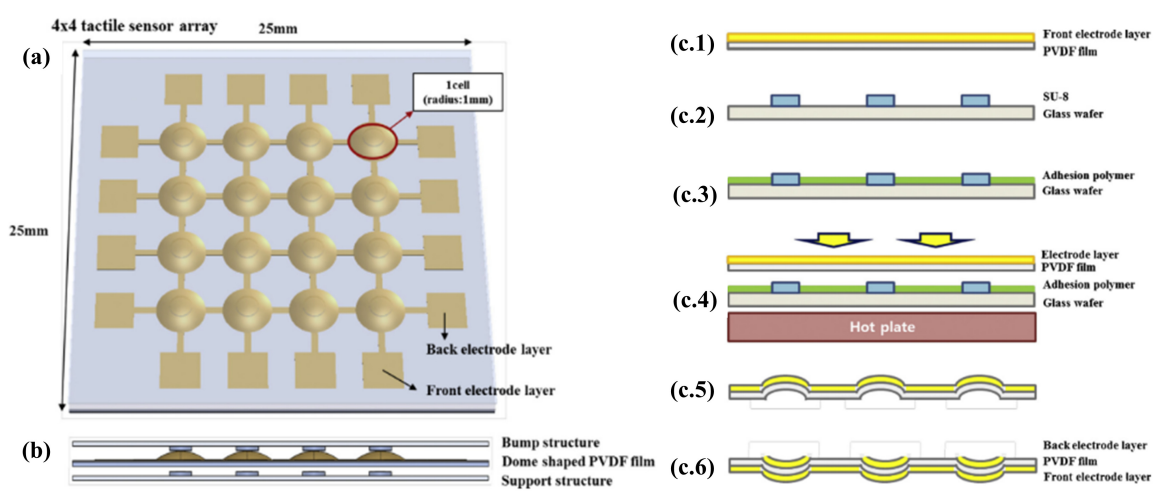

Figure 5. Tactile sensor array fabricated by inflation technique. Conceptual (a) front and (b) side views and (c) fabrication steps for the tactile sensor array. Reproduced from Kim et al. [30] with permission of Elsevier B.V.

A stress-driven approach was implemented by Akhbari et al. [43]. They analytically and experimentally demonstrated improved electromechanical coupling properties of self-curved transducers, made of a $2 \mu \mathrm{m}$-thick aluminum nitride layer sandwiched between bottom and top 
metal electrodes, whose thickness was $150 \mathrm{~nm}$, exploiting a self-generated curvature due to residual stress in the films. A multi-layer of $0.65 \mu \mathrm{m}$ silicon nitride and Low Temperature Oxide (LTO) on top of $4 \mu \mathrm{m}$ silicon has resulted in the desirable self-curved diaphragms by exploiting the residual compressive stress $(\approx 180 \mathrm{MPa})$. Backside Deep Reactive Ion Etching (DRIE) was then used to release the self-curved diaphragm, which bends in a concave form. Finally, the active layers were deposited. The concave-shape diaphragm fabricated by Akhbari et al. [43] and the corresponding process flow are shown in Figure 6.
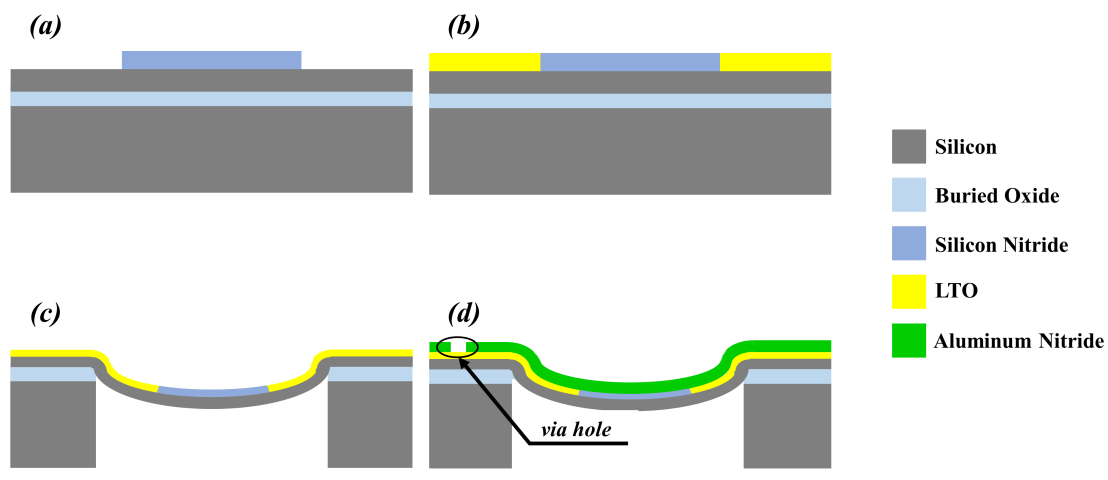

Aluminum Nitride

Figure 6. Cross-sectional view of the concave-shape pMUT (piezoelectric Micromachined Ultrasonic Transducer) generated by compressive residual stress of SiN and Low Temperature Oxide (LTO). (a) SiN deposition and patterning; (b) LTO deposition and Chemical Mechanical Polishing (CMP); (c) backside etching to form the diaphragm; (d) Mo/AlN/Mo deposition. Based on Akhbari et al. [43].

A different process was reported by Mastronardi et al. [27,28]. They designed and fabricated aluminum nitride-based domed circular membranes using the following standard microfabrication process. A Mo/AlN/Mo material stack was deposited on a general purpose Kapton $\mathrm{HN}^{\mathrm{TM}}\left(\mathrm{DuPont}^{\mathrm{TM}}\right)$ flexible substrate, previously laminated on a silicon wafer that acted as rigid support during the microfabrication steps. The AlN thin film, with a thickness of about $1 \mu \mathrm{m}$, was deposited at moderately high temperature (about $250-300^{\circ} \mathrm{C}$ ) through reactive sputtering from a highly pure Al target. After a first masking photolithography, the top Mo and the AIN layers were etched into a circular shape by ICP etching. Next, the Mo bottom common electrode was patterned. In order to define the top electrodes, an additional metal deposition, followed by lift-off patterning was performed. Electrical connections were bonded in a subsequent step. Finally, to prevent external mechanical damages and to electrically isolate the piezoelectric transducers, a parylene $C$ coating of $1 \mu \mathrm{m}$ was deposited via chemical vapor deposition. The conformal nature of the parylene $C$ coating allowed a full electrical and mechanical isolation of the final device.

\section{Results and Applications}

In this section, results and application examples of the previously described stress-driven MEMS structures for flow and tactile sensing are described. It will be shown that the stress-driven design or the ability to introduce change in the flexural bending stiffness of multilayered structures are the key points for setting up a specific mechanical behavior of the artificial sensor. A proper functional and morphological design combined with a detection principle (piezoresistive or piezoelectric) and the choice of the manufacturing strategy as described in the previous section is the way to achieve devices that are able to mimic and recreate the capabilities of biological sensors.

\subsection{Piezoresistive Flow Sensing: Mimicking the Biological Lateral Line Organ}

Over the course of evolution, fish have evolved a special sensory organ ideally adapted to their aquatic environment: the lateral line organ offers valuable information about the adjacent water 
movement by detecting changes in the pressure and water flow along the body. This so-called "distant touch" forewarns fish of predators, helps to avoid obstacles and may play a role in saving energy during underwater locomotion [44,45].

The individual sensory receptors in the lateral line organ, hair-like structures called neuromasts, detect the tiniest differences in pressure and perceive fractional changes of the flow velocity [46]. As a general functional principle, water flows around the neuromasts and bends their jellylike cupula protruding into the fluid. This flexible bending causes a mechanical deflection of the membrane cilia of hair cells, which are located inside the cupula, either leading to an excitation or an inhibition of a neuronal stimulus, depending on the direction of deflection.

From an engineering and biomimetics perspective, the implementation of an artificial lateral line system, inspired by how nature has solved the problem in fish, is a promising approach to explore hydrodynamics and to test the hypothesis that lateral line sensing can improve the propulsion efficiency, sensing capability and feedback control systems in underwater vehicles.

\subsubsection{Bio-Inspired Artificial Hair Cells}

Artificial lateral line flow sensing applications require hair-like structures with a length enough to reach into the laminar flow layer above the vehicle's skin. Production processes employed in microsystems technology allow for sufficient miniaturization of the components required to develop bio-inspired artificial hair cells with the required dimensions. Various piezoresistive-based sensor design methodologies and MEMS fabrication processes for producing hair cell-like flow sensors have been developed in various laboratories world-wide, as thoroughly described in several comprehensive literature reviews [47-51]. Table 1 gives a comparative overview of piezoresistive-based sensor design methodologies by listing achieved hair geometries, aspect ratios and flow velocity-related performance indicators. Early successes were achieved with bare vertical beams and pillar structures. Subsequent improvement in the available manufacturing processes has made it possible to implement various microstructures, such as dome-like cupulae, pillars capped with hydrogels, bent cantilevers and flags and, most recently, interconnected carbon nanotube bundles [52].

Wang et al. [7] performed a systematic investigation to characterize their MEMS-based air flow sensor, as shown in Figure 7. Tests with three different cantilever beam lengths $(400 \mu \mathrm{m}$, $1200 \mu \mathrm{m}$ and $2000 \mu \mathrm{m}$ ) were performed in a wind tunnel at airflow velocities ranging between 0 and $\approx 45 \mathrm{~m} \mathrm{~s}^{-1}$ (maximum detectable flow rate). The resistance signal generated by the flow sensors increased approximately linearly with increasing airflow velocity, and flow rate sensitivity increased with increasing cantilever beam widths. Average sensitivities were found to be $0.0134,0.0227$ and $0.0284 \Omega \mathrm{m}^{-1} \mathrm{~s}$, respectively.

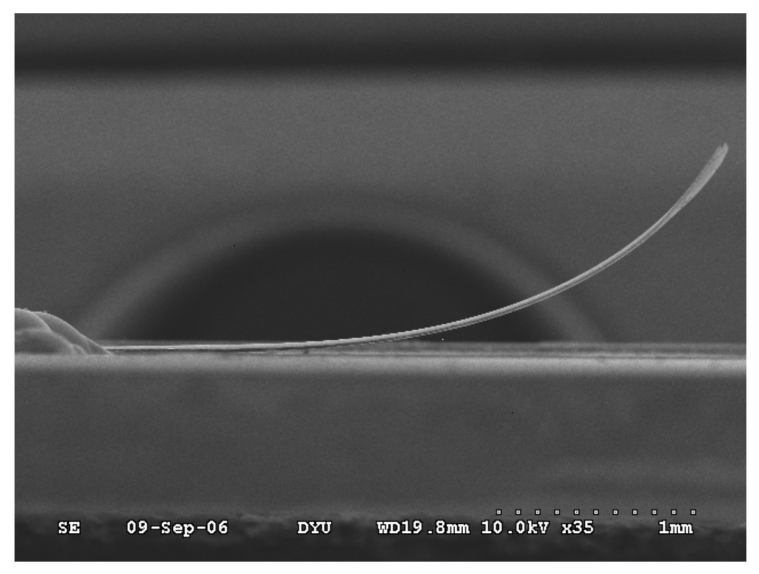

Figure 7. Side view scanning electron microscope image. MEMS-based air flow sensor with a free-standing microcantilever structure. Reproduced from Wang et al. [7]. 
Table 1. Previously described piezoresistive based hair cell-like flow sensors ordered by year of publication. Comparative overview of hair geometries, aspect ratios and flow velocity related performance indicators (sensitivity, measurement range).

\begin{tabular}{|c|c|c|c|}
\hline Authors & Hair Geometry $^{a}$ & Aspect Ratio & Performance $b, c$ \\
\hline Ozaki et al. (2000) [53] & $\begin{array}{l}\text { Vertical beam } \\
(3000 \times 250 \times 8 \mu \mathrm{m})\end{array}$ & $12: 1$ & $\mathrm{n} / \mathrm{a}$ \\
\hline Ozaki et al. (2000) [53] & $\begin{array}{l}\text { Vertical pillar } \\
(800 \times 230 \times 10 \mu \mathrm{m})\end{array}$ & $3.5: 1$ & $\mathrm{n} / \mathrm{a}$ \\
\hline $\begin{array}{l}\text { Fan et al. (2002) [54], } \\
\text { Chen et al. (2003) [55] }\end{array}$ & $\begin{array}{l}\text { Vertical beam } \\
(820 \times 100 \times 10 \mu \mathrm{m})\end{array}$ & $8.2: 1$ & $\mathrm{n} / \mathrm{a}$ \\
\hline Engel et al. (2005) [56] & $\begin{array}{l}\text { Vertical pillar } \\
(3000 \times 500 \mu \mathrm{m})\end{array}$ & $6: 1$ & $\mathrm{~S}=245 \mathrm{ppm} / \mu \mathrm{m}$ \\
\hline $\begin{array}{l}\text { Tucker et al. (2006) [57], } \\
\text { Chen et al. (2007) [58] }\end{array}$ & $\begin{array}{l}\text { Vertical pillar } \\
(600 \times 80 \mu \mathrm{m})\end{array}$ & $7.5: 1$ & $\begin{array}{l}\mathrm{S}_{\text {water }, A C}=200 \mu \mathrm{m} \mathrm{s}^{-1} \\
\mathrm{~S}_{\text {water }, D C}=100 \mu \mathrm{m} \mathrm{s}^{-1}\end{array}$ \\
\hline Peleshanko et al. (2007) [59] & $\begin{array}{l}\text { Dome-like cupula } \\
(750 \times 1500 \mu \mathrm{m})\end{array}$ & $1: 2$ & $\mathrm{~S}_{\text {water }}=75 \mu \mathrm{ms}^{-1}$ \\
\hline Wang et al. (2007) [7] & $\begin{array}{l}\text { Bent cantilever } \\
(4000 \times 400 \times 1 \mu \mathrm{m})\end{array}$ & $10: 1$ & $\begin{array}{l}\mathrm{S}_{a i r}=0.0284 \Omega /\left(\mathrm{m} \mathrm{s}^{-1}\right) \\
\mathrm{R}_{\text {air }}=0-45 \mathrm{~m} \mathrm{~s}^{-1}\end{array}$ \\
\hline Wang et al. (2008) [15] & $\begin{array}{l}\text { Bent cantilever } \\
(4450 \times 200 \times 20 \mu \mathrm{m})\end{array}$ & 22.3:1 & $\mathrm{n} / \mathrm{a}$ \\
\hline Aiyar et al. (2009) [60] & $\begin{array}{l}\text { Bent flag } \\
(1500 \times 400 \times 7.6 \mu \mathrm{m})\end{array}$ & $3.8: 1$ & $\begin{array}{l}\mathrm{S}_{a i r}=66 \Omega /\left(\mathrm{m} \mathrm{s}^{-1}\right) \\
\mathrm{R}_{\text {air }}=0-16.9 \mathrm{~m} \mathrm{~s}^{-1}\end{array}$ \\
\hline Du et al. (2009) [61,62] & $\begin{array}{l}\text { Cantilever } \\
(500 \times 500 \times 10 \mu \mathrm{m})\end{array}$ & $1: 1$ & $\mathrm{~S}_{\text {air }}=60 \mu \mathrm{V} /\left(\mathrm{m} \mathrm{s}^{-1}\right)$ \\
\hline McConney et al. (2009) [63] & $\begin{array}{l}\text { Capped vertical pillar } \\
(825 \times 165 \mu \mathrm{m})\end{array}$ & $5: 1$ & $\begin{array}{l}\mathrm{S}_{\text {water,bare }}=100 \mu \mathrm{m} \mathrm{s}^{-1} \\
\mathrm{~S}_{\text {water, } \text {,apped }}=2.5 \mu \mathrm{m} \mathrm{s}^{-1}\end{array}$ \\
\hline Song et al. (2009) [64] & $\begin{array}{l}\text { Bent flag } \\
(3500 \times 600 \times 8.2 \mu \mathrm{m})\end{array}$ & $5.8: 1$ & $\begin{array}{l}\mathrm{S}_{\text {air }}=14.5 \mathrm{mV} /\left(\mathrm{m} \mathrm{s}^{-1}\right) \\
\mathrm{R}_{\text {air }}=0-12 \mathrm{~m} \mathrm{~s}^{-1}\end{array}$ \\
\hline $\begin{array}{l}\text { Zhou et al. (2009) [37], } \\
\text { Zhang et al. (2010) [9] }\end{array}$ & $\begin{array}{l}\text { Bent cantilever } \\
(100 \times 20 \times 1 \mu \mathrm{m})\end{array}$ & $5: 1$ & $\begin{array}{l}\mathrm{S}_{\text {water }}=1.5-3.5 \Omega /\left(\mathrm{cm} \mathrm{s}^{-1}\right) \\
\mathrm{R}_{\text {water }}=0-0.23 \mathrm{~m} \mathrm{~s}^{-1}\end{array}$ \\
\hline Qualtieri et al. (2011) [26] & $\begin{array}{l}\text { Bent cantilever } \\
(600 \times 100 \times 0.7 \mu \mathrm{m})\end{array}$ & $6: 1$ & $\mathrm{n} / \mathrm{a}$ \\
\hline Qualtieri et al. (2012) [38] & $\begin{array}{l}\text { Bent cantilever } \\
(1500 \times 100 \times 4 \mu \mathrm{m})\end{array}$ & $15: 1$ & $\begin{array}{l}\mathrm{S}_{\text {water }}=0.7 \mathrm{mV} /\left(\mathrm{cm} \mathrm{s}^{-1}\right) \\
\mathrm{R}_{\text {water }}=0.05-0.35 \mathrm{~m} \mathrm{~s}^{-1}\end{array}$ \\
\hline Yilmazoglu et al. (2016) [52] & $\begin{array}{l}\text { Vertical beam } \\
(500 \times 350 \times 100 \mu \mathrm{m})\end{array}$ & $1.4: 1$ & $\mathrm{~S}=2100 \mathrm{ppm} / \mu \mathrm{m}$ \\
\hline
\end{tabular}

${ }^{a}$ Hair geometry defined as product of length $\times$ width (or diameter) $\left(\times\right.$ thickness); ${ }^{b} \mathrm{R}=$ dynamic range, $\mathrm{S}=$ sensitivity, $\mathrm{n} / \mathrm{a}=$ not available $;{ }^{\mathrm{c}} \mathrm{ppm} / \mu \mathrm{m}=$ resistance change in parts per million per $\mu \mathrm{m}$ of tip deflection.

Zhang et al. [9] used deionized water to calibrate their self-bended piezoresistive microcantilever flow sensors. Micro-cantilevers with beam lengths of $100 \mu \mathrm{m}, 200 \mu \mathrm{m}$ and $400 \mu \mathrm{m}$ were fabricated, as shown in Figure 8. Varying flow rates between of 0 and $0.2 \mathrm{~m} \mathrm{~s}^{-1}$ were applied to test the performance under controlled conditions. The results revealed that the microcantilever was able to measure small flow rate between 0 and $0.23 \mathrm{~m} \mathrm{~s}^{-1}$, with a sensitivity ranging between 1.5 and $3.5 \Omega \mathrm{cm}^{-1} \mathrm{~s}$. 


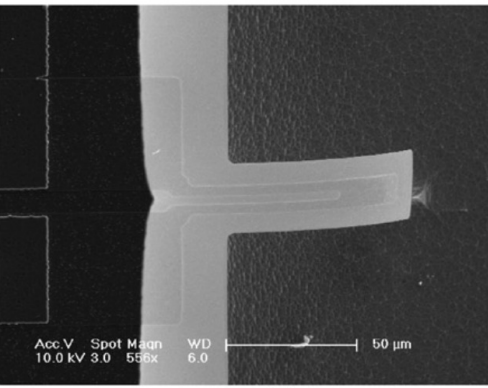

(a)

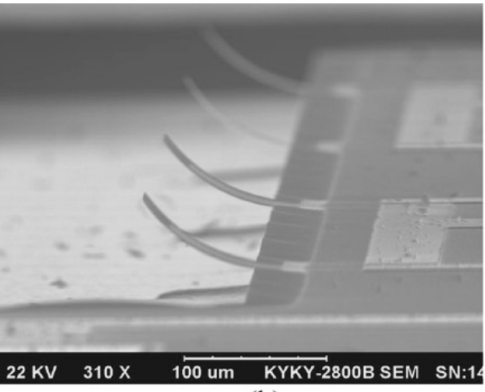

(b)

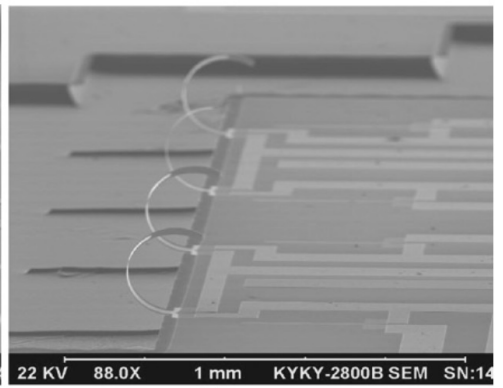

(c)

Figure 8. Scanning electron microscope images of curved-up microcantilever flow sensors. (a) Single $100 \mu \mathrm{m}$ microcantilever, (b) $100 \mu \mathrm{m}$ microcantilever array and (c) $400 \mu \mathrm{m}$ microcantilever array. Adapted from Zhang et al. [9] with permission of Elsevier B.V.

The stress-driven artificial hair cell described by Qualtieri et al. [38] was tested and calibrated in continuous water flow up to $0.5 \mathrm{~m} \mathrm{~s}^{-1}$. A scanning electron microscope image of the artificial hair cell is presented in Figure 9. The SiN/Si-based cantilever reaches approximately $1.2 \mathrm{~mm}$ tip height above the base layer. A thin hydrophobic parylene layer covers and securely waterproofs the entire surface of the sensor $[14,38]$. Figure 10 shows the electrical behavior of the flow sensor with varying material thicknesses in a continuous water flow. The relative sensor signal is plotted as a function of water flow velocity. The varying curve shapes demonstrate that the sensitivity of the flow sensor to a specific dynamic range can be tuned by choosing the parylene thickness accordingly. Different material thicknesses resulted in varying beam flexural stiffnesses, which in turn, generated varying signal amplitudes. Sample A (parylene coating, $0.5 \mu \mathrm{m}$ ) showed a sub-linear (strain-hardening) behavior with a linear sensitivity of $\approx 0.2 \mathrm{~V} \mathrm{~m}^{-1} \mathrm{~s}$ at flow velocities lower than $0.20 \mathrm{~m} \mathrm{~s}^{-1}$. In comparison, Samples B (parylene coating, $2 \mu \mathrm{m})$ and $\mathrm{C}\left(\mathrm{Si}_{x} \mathrm{~N}_{y}\right.$ layer, $\left.0.3 \mu \mathrm{m}\right)$ showed a super-linear (strain-softening) behavior with a linear sensitivity of $\approx 0.07$ and $0.9 \mathrm{~V} \mathrm{~m}^{-1} \mathrm{~s}$, respectively, at higher flow velocities between 0.25 and $0.35 \mathrm{~m} \mathrm{~s}^{-1}$.

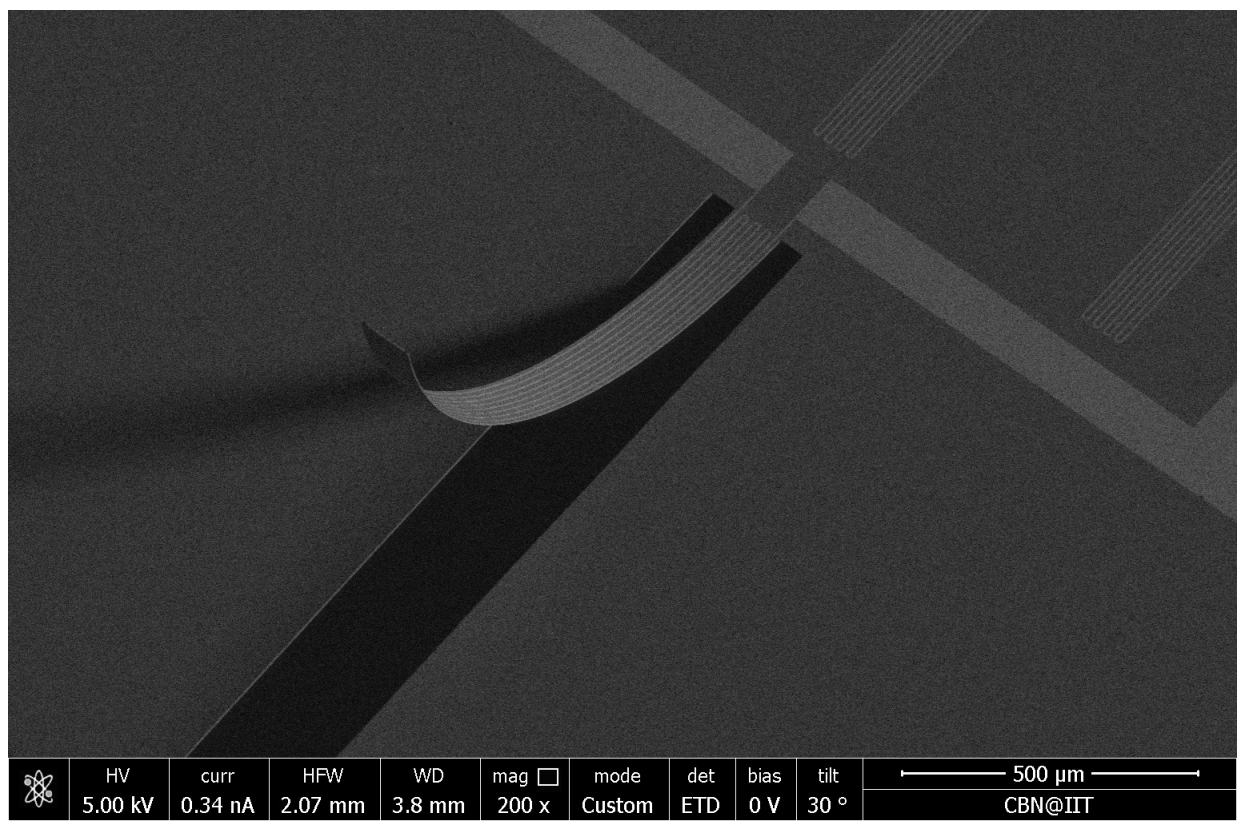

Figure 9. Scanning electron microscope image of the silicon nitride-based cantilever at $200 \times$ magnification. The released SiN/Si bilayer is $2.3 \mu \mathrm{m}$ thick and reaches approximately $1.2 \mathrm{~mm}$ tip height above the base layer. 

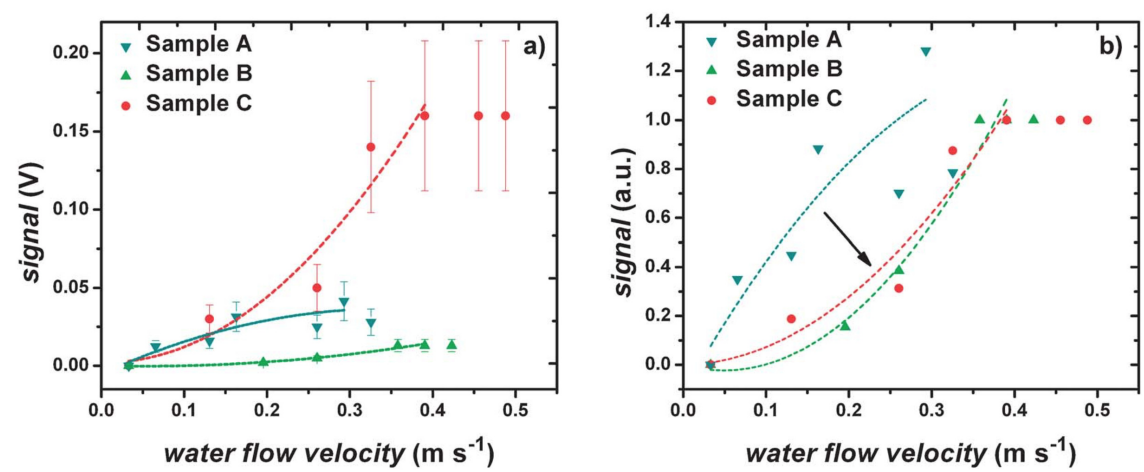

Figure 10. Electrical behavior of three flow sensors with varying material thicknesses under continuous water flow conditions. The $0.5 \mu \mathrm{m}$ parylene coating (Sample A), $2 \mu \mathrm{m}$ parylene coating (Sample B) and $0.3 \mu \mathrm{m} \mathrm{Si}{ }_{x} \mathrm{~N}_{y}$ layer (Sample C). The dashed lines are intended as a visual guideline. (a) The different coating material characteristics result in varying calibration curve shapes, tuning from a sub-linear (strain-hardening) to a super-linear (strain-softening) trend. A common signal saturation region is shown. (b) Normalized output signal: the arrow highlights the different behaviors of the calibration curve, going from lower to higher flexural stiffness. Reproduced from Rizzi et al. [14] with permission of The Royal Society of Chemistry.

\subsubsection{Artificial Lateral Line Flow Rate and Velocity Sensing}

Klein and Bleckmann [65] and Herzog et al. [66,67] described a bio-inspired flow rate sensor that uses an optical measuring method to be applied in tap water systems and medical and pharmaceutical applications. As shown in Figure 11, a single artificial flow sensor was embedded in a canal and consisted of a lamella. An LED was attached above the canal and coupled light into the lamella, which in turn was converted into electricity by a photodiode positioned at the bottom side. When water streamed in the canal, the lamella either deflected by a constant angle causing a steady signal (in case of steady laminar flow) or the vibrations of the lamella caused an unsteady, vibrating and oscillating signal (in case of turbulent flow with fluctuations and unsteadiness).

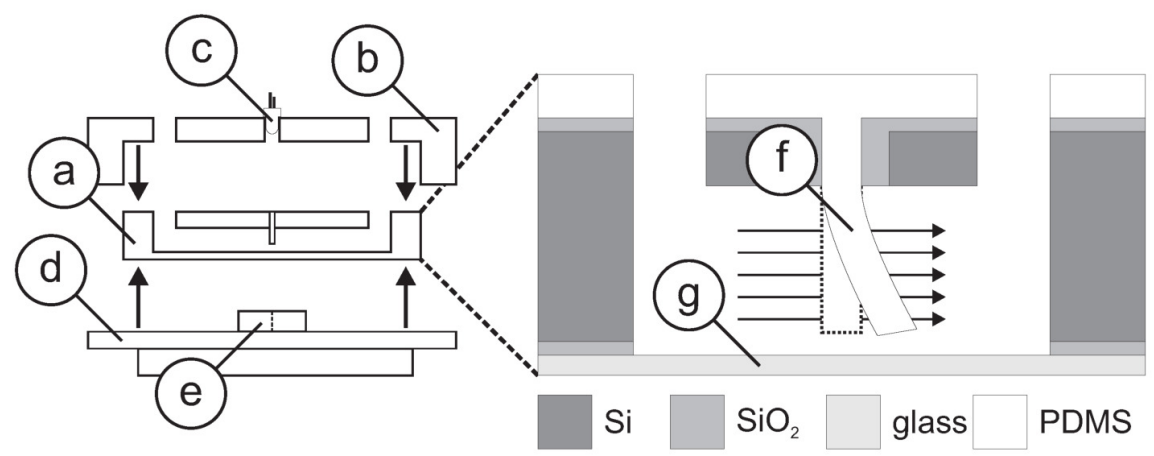

Figure 11. Assembly of a micro-machined optical-based flow sensor. (a) Si-chip; (b) housing; (c) LED; (d) electronics PCB; and (e) optical detector. Magnification: Si-chip featuring a (f) PDMS lamella and (g) glass plate. Dimensions not to scale. Reproduced from Herzog et al. [66].

Wang et al. [15] positioned four freestanding micro-cantilever beams (as described in Section 3.1) perpendicular to each other to detect flow rate and direction. When air propagated through the sensor array, the resulting beam deformation caused resistance variation among the individual cantilever beams ( $4000 \mu \mathrm{m}$ long and $400 \mu \mathrm{m}$ wide), which was used to determine air flow direction. When the air propagated through the sensor array in parallel to two opposing beams, the largest resistance variation was found for the downwind cantilever, while the least resistance variation was caused by the upwind 
cantilever. The resistance variations of the two cantilever beams positioned perpendicular to the air flow direction were almost equal to zero. Furthermore, it was shown that flow rate can be determined by calculating the total resistance variations for the four cantilevers. For two given flow directions (i.e., $135^{\circ}$ and $180^{\circ}$ as shown in [15]), the sum of the absolute values of the resistance variation was equal and just depended on the flow rate.

In the flow sensing application described by Abels et al. [68], a linear array of closely separated stress-driven artificial hair cells was designed that features multi-parameter flow measurements to be used as input for an underwater vehicle's control procedure. The flow sensing array consisted of multiple flow sensors in a line along the cantilever beam direction. Figure 12 gives a simplified systematic overview of the experimental setup. A real-time capable cross-correlation procedure was developed, which extracts freestream flow direction and velocity information from flow fluctuations. When flow fluctuations (or pulses) propagated through the sensor array, similar, but time-shifted flow signals were detected by the individual sensors. By cross-correlating multiple sensor signals, relevant information about local flow velocities in the sensor array, as well as propagation velocity, linear forward/backward direction along the cantilever beam orientation and periodicity of pulses or pulse trains was extracted. In general, flow velocity information was in strong agreement with a commercial system. The computed flow velocities deviated from the commercial system by $0.09 \mathrm{~m} \mathrm{~s}^{-1}$ for $0.5 \mathrm{~m} \mathrm{~s}^{-1}$ flow velocity and by $0.15 \mathrm{~m} \mathrm{~s}^{-1}$ for $1.0 \mathrm{~m} \mathrm{~s}^{-1}$ flow velocity. In case very high accuracy is required by the technical application, precise information about velocity components of the flow can be computed for signal-to-noise ratios down to about 2.5 or five, in case of filtered or unfiltered signals, respectively.

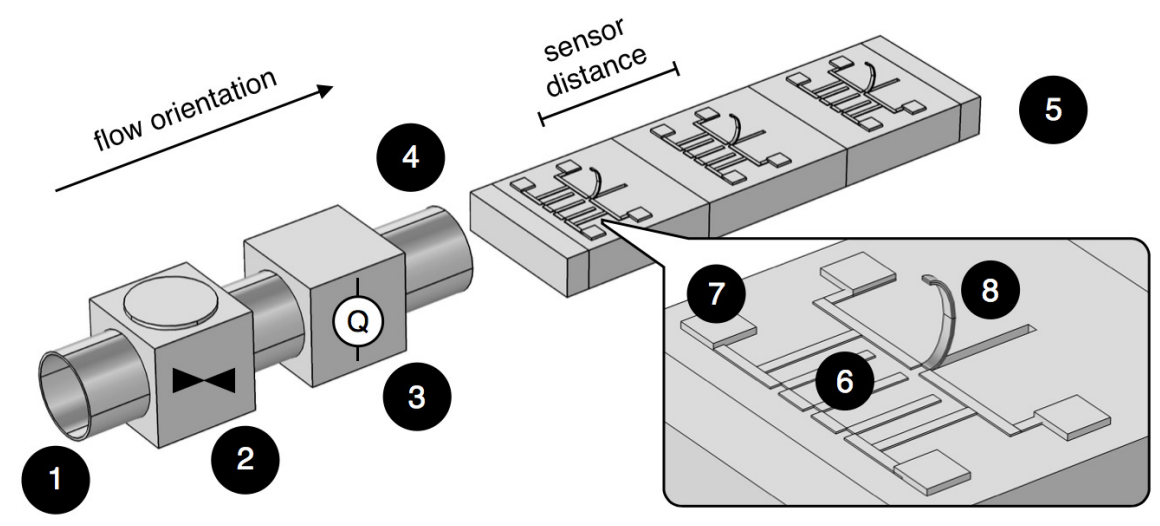

Figure 12. Simplified systematic overview of the experimental setup. Flow pulses pass the following components: (1) non-flexible tubing; (2) mechanical valve; (3) commercial flow rate sensor; (4) tube outlet; and (5) artificial lateral line system with artificial hair cell sensors positioned in a line. Magnification: (6) piezoresistors; (7) contact pads; and (8) cantilever beam. Flow orientation and sensor distance are indicated. Dimensions not to scale. Reproduced from Abels et al. [68] with permission of IOP Publishing.

\subsection{Piezoelectric Tactile Sensing: Mimicking the Human Tactile Sense}

The human tactile sense is an extremely accurate and sensitive active organ. It is responsible for detecting mechanical stimuli in a pressure range from 10-100 kPa, in addition to thermal and other stimuli, that typically occur during the dexterous manipulation of objects, providing information about contact forces, distribution and torques and allowing for the identification of object properties, such as geometry, stiffness and texture $[69,70]$. Tactile receptors are usually classified as mechanoreceptors, being able to convert the mechanical deformations caused by forces, vibrations or slip of the skin and objects into electrical nerve impulses. When the skin is deformed, the corresponding deformation is transmitted from the surface to the mechanoreceptor's plasma membrane causing the generation of a graded potential and, in turn, corresponding spikes of action potentials [71,72]. Human skin 
and especially the fingertips contain different types of tactile sensors, which can be categorized according to the nature of the stimulus they detect: static or dynamic mechanoreceptors. While static receptors are sensitive to temporally constant pressure, dynamic sensors are responsive to time-variant stimuli $[73,74]$.

From an engineering point of view, humanoid robots need tactile interfaces to perform complex tasks in unstructured environments and for safely interacting with humans in daily and routinely executed activities, such as assistance, support and coexistence. Bio-mimicking abilities of the human tactile system and performing advanced in-hand manipulation tasks are made possible by detecting static forces, as well as dynamic forces, such as normal and tangential contact for gathering spatial and geometrical information from surface exploration. Arrays of pressure-sensitive sensors could be integrated into an electronic skin to complement the desirable properties of flexibility, conformability and stretchability in improving anthropomorphism [75,76].

\subsubsection{Tactile Sensors}

In the last decade, the development of flexible materials for tactile sensing applications has attracted an increasing interest in robotics, industrial and manipulation applications, prosthetic and orthotic devices and tools for the evaluation of tissue stiffness and for preventing damage [29-31,33,39,40]. Achieving high spatial resolution and reliability by means of a large-area artificial skin-like sensory system is a priority for the enhancement of robots' capabilities and their safe interaction with humans and objects with sufficient sensitivity in a wide pressure range (10-100 kPa). In this regard, aluminum nitride (AlN), a wide band-gap piezoelectric material, stands out as a useful candidate for artificial skin applications. Advantages such as low actuation voltages (1-10 V) and easy integration on CMOS technology and flexible substrates are key features of this technology.

Piezoelectric micromachined transducers are of great importance as measurement tools for pulse-echo ultrasonics applications in robotics, medical diagnostic and proximity detection [77-80]. Here, the ultrasonic transducer, behaving as a transmitter/receiver, is typically embedded in a soft material layer that can be deformed by an applied pressure. The pulse generated by the transmitter and propagating through the soft covering is reflected back by the target and collected by the same piezoelectric transducer (the receiver), such that it is possible to know the transit time of the signal, which is proportional to the thickness of the deformed material and, hence, to the applied load. Contact parameters can be detected also by measuring the change in resonance frequency of the sensor, allowing the detection of the hardness and/or compliance of objects. Flexure modes of piezoelectric membranes can be exploited to cover ultrasonic frequency ranges that extend from $100 \mathrm{kHz}-50 \mathrm{MHz}$.
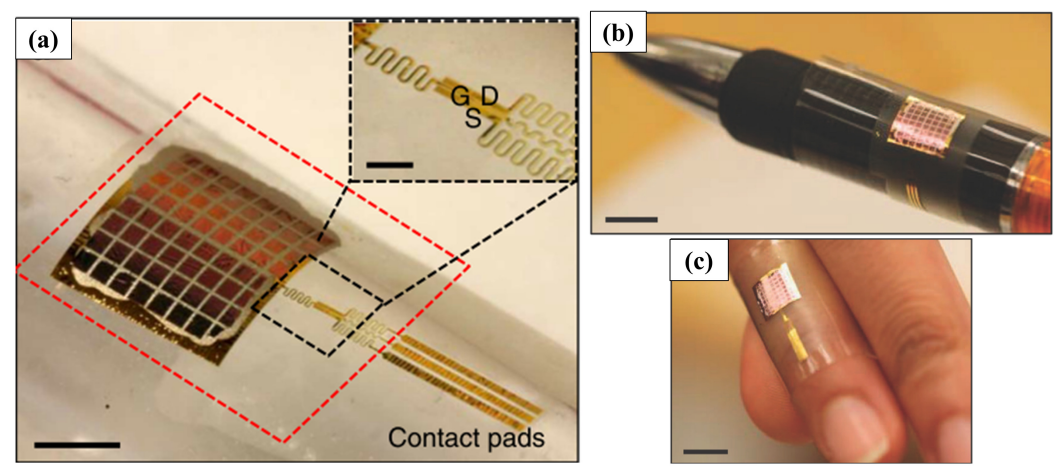

Figure 13. Photographs of a thin conformable piezoelectric pressure sensor. (a) Device wrapped on a cylindrical glass support (scale bar, $5 \mathrm{~mm}$ ); (b) sensor wrapped on a pen; and (c) a finger (scale bar, $10 \mathrm{~mm}$ ). Reproduced from Dagdeviren et al. [39] with permission of Macmillan Publishers Limited. 
Using flat tactile pressure sensors that exploit the dependence of the piezoelectric voltage on the contact force, Dagdeviren et al. [39] (as shown in Figure 13) used an array of piezoelectric square membranes to make a precision skin-mounted sensor to measure pressures in a very low load range from $2-10 \mathrm{mN}$ with a dynamic sensitivity of about $11.6 \mathrm{mV} \mathrm{N}^{-1}$ and a minimum detected force of $\approx 2 \mathrm{mN}$ (see Table 2). Khan et al. [31] exploited the changes in the polarization level of the P(VDF-TrFE) to measure the contact forces and detect dynamic tactile parameters. The array was able to detect contact forces in a range of [400-4000] $\mathrm{mN}$ with a dynamic sensitivity of $\approx 500 \mathrm{mV} \mathrm{N}^{-1}$ and a minimum detected force of $200 \mathrm{mN}$.

An improvement in the sensitivity of piezoelectric tactile sensors can be achieved by adding complexity to the geometry of the sensor. Kim et al. [30] fabricated a dome-shaped piezoelectric tactile sensor (Figure 14) with films of $56 \mu \mathrm{m}$-thick PVDF whose achieved sensitivity can reach values up to $8830 \mathrm{mV} \mathrm{N}^{-1}$ (according to the geometry and curvature of domes), showing an increase of about $46 \%$ of the sensitivity compared to the conventional flat counterpart.

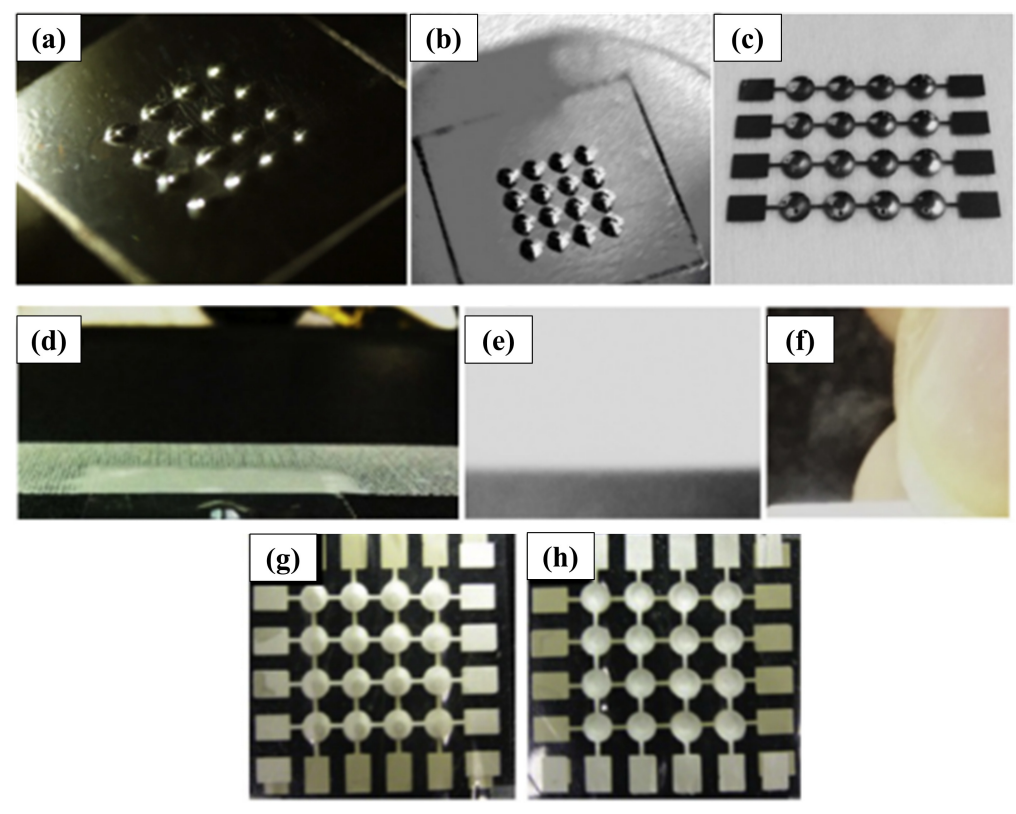

Figure 14. Optical photographs of the fabricated dome-shaped PVDF film and tactile sensors. (a-f) The fabricated dome-shaped PVDF film (height $=500 \mu \mathrm{m})$. $(\mathbf{g}$,h) The proposed dome-shaped tactile sensor. Reproduced from Kim et al. [30] with permission of Elsevier B.V.

As illustrated in Figure 15, an array of $2 \times 2$ aluminum nitride-based tactile transducers, hereafter named DSDT (Dome-Shaped Diaphragm Transducer), was designed and manufactured using a standard micromachining process on $25 \mu \mathrm{m}$-thick polyimide flexible substrate (see Section 3.2) $[27,81,82]$. The unit cell consists of flexible piezoelectric circular membranes made of c-axis highly-oriented AlN embedded between Mo metal electrodes in order to collect the charges generated by virtue of the direct piezoelectric effect. The stress release of the active layers (AlN and Mo marginally) generates uplifted and circular domes with structural stiffness well below the stiffness of the component materials (up to $3.5 \mathrm{~N} \mathrm{~mm}^{-1}$ ). The overall effect is an improvement of the electromechanical response of the piezo-cells: the lower the stiffness of the dome as a whole, the lower the minimum threshold for contact force detection and the larger the overall dynamic range of detection. The uplifted area is thus determinant for the low stiffness and dynamic range of the transducer that easily deforms under loading. The natural organization in the dome structure is due to the stress difference of AlN over the polyimide, which leads to a lifting up of the circular structures from the substrate surface. The sensing mechanism of the transducer mainly relies on the dome shape; when a normal force is applied on the top of the dome, a mechanical stress occurs in the AlN thin 
layer that becomes electrically polarized due to synergistic interaction between piezoelectric and flexoelectric effects, making possible the measurement of periodic impulsive mechanical stimuli. The domes are first pushed downwards, with slight compression in the softer polyimide substrate tape. Then, the released structure is flattened on the silicon substrate. In this region, the stress is transferred to the piezoelectric film, generating the voltage signal, that goes to saturation caused by a constant flattening of the active piezoelectric layer. The dielectric properties of the MIM (Mo/AlN/Mo) stack, which behaves as a capacitor, also make possible the measurement of long time frame static mechanical stimuli by a steady deformation of the convex structure [27].
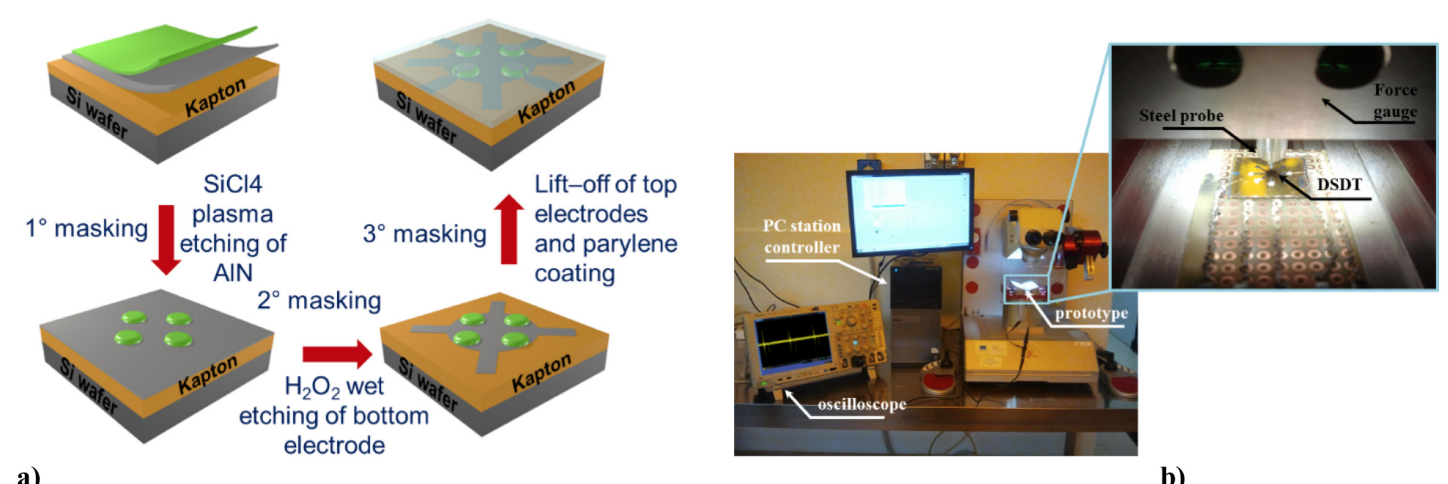

a)

Figure 15. An array of $2 \times 2$ aluminum nitride-based tactile transducers. (a) Dome-shaped diaphragm transducers have been designed and realized by a standard micromachining process; (b) computer and probe station used for measurements and calibration. Reproduced from Mastronardi et al. [27] with permission of AIP Publishing.

a)

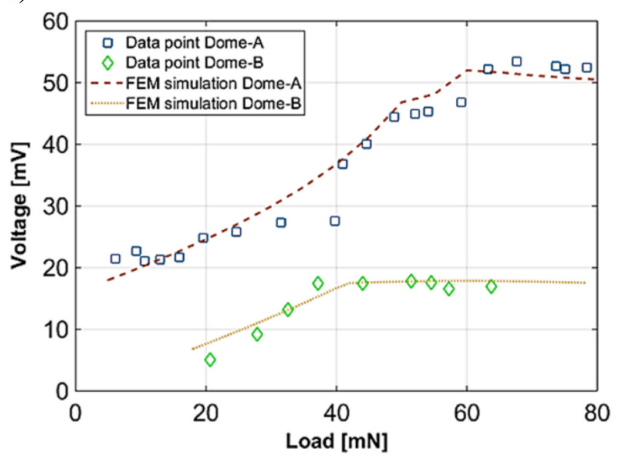

b)

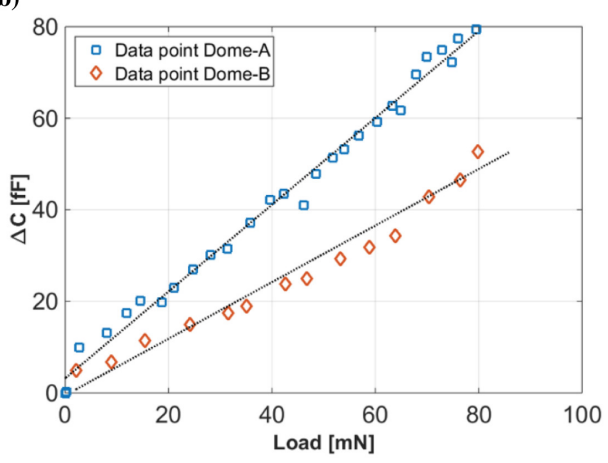

Figure 16. Electrical characterization of dome-shaped devices with different releasing heights. (a) The output voltage at the peak is reported vs. the applied force (Dome A, height $h \approx 43 \mu \mathrm{m}$, uplifted radius $r_{u p} \approx 1.5 \mathrm{~mm}$ and stiffness $k_{s} \approx 3.5 \mathrm{~N} \mathrm{~mm}^{-1}$; Dome B, height $h \approx 33 \mu \mathrm{m}$, uplifted radius $r_{u p} \approx 1.2 \mathrm{~mm}$ and stiffness $k_{s} \approx 9.7 \mathrm{~N} \mathrm{~mm}^{-1}$ ); (b) the detection of long static stimuli has been experimentally and analytically observed as capacitance decrease at increasing forces up to $80 \mathrm{mN}$ of contact force. Reproduced from Mastronardi et al. [27] with permission of AIP Publishing.

\subsubsection{Tactile Sensing System}

Dome-shaped devices with different releasing height (Dome A, height $h \approx 43 \mu \mathrm{m}$, uplifted radius $r_{u p} \approx 1.5 \mathrm{~mm}$ and stiffness $k_{s} \approx 3.5 \mathrm{~N} \mathrm{~mm}^{-1}$; Dome B, height $h \approx 33 \mu \mathrm{m}$, uplifted radius $r_{u p} \approx 1.2 \mathrm{~mm}$ and stiffness $k_{s} \approx 9.7 \mathrm{~N} \mathrm{~mm}^{-1}$ ) were electrically characterized, as reported in Figure 16, where the output voltage at the peak is reported vs. the applied force (Figure 16a). As can be seen from the plots 
in Figure 16a,b, the electromechanical response of the domes is related to the radius of the uplifted area: the larger the radius of the outer dome area (the region not covered by piezoelectric material), the higher the sensitivity of the sensor to lower forces because of the combination of piezoelectric and flexoelectric effects. On the other hand, domes with smaller uplifted area have shown lower measured offset, because of a less significant flexoelectric contribution. Measurements show an increase of generated voltage in a dynamic range of [0-60 mN]. For higher applied forces, the devices start to saturate. Nevertheless, the minimum force detected is $1.2 \mathrm{mN}$. The detection of long static stimuli (Figure 16b) was experimentally and analytically observed as a capacitance decrease at increasing contact forces of up to $80 \mathrm{mN}$. The capacitance variation was observed for the whole interval of application of the stress (1 s), and it did not decay with time; therefore, the measurement of static forces is possible in the same system, making the AlN thin film in the dome structure a multifunctional material.

An exhaustive comparison of the technologies based on aluminum nitride and other different approaches, still based on piezoelectric transduction methods, for the development of tactile sensors is reported in Table 2, and the comparison is displayed graphically in Figure 17.

Table 2. Comparison between different technological approaches for force detection in tactile applications.

\begin{tabular}{|c|c|c|c|c|c|c|c|c|}
\hline Authors & Material & Shape & $\begin{array}{l}\text { Spatial } \\
\text { Res. a } \\
(\mathrm{mm})\end{array}$ & $\begin{array}{l}\text { Min. } \\
\text { Force } \\
(\mathrm{mN})\end{array}$ & $\begin{array}{l}\text { Dynamic } \\
\text { Sensitivity } \\
\left(\mathrm{mV} \mathrm{N}^{-1}\right)\end{array}$ & $\begin{array}{l}\text { Static } \\
\text { Sensitivity } \\
\left(\text { fF } N^{-1} \text { ) }\right.\end{array}$ & $\begin{array}{l}\text { Load } \\
\text { Range } \\
(\mathrm{mN})\end{array}$ & $\begin{array}{l}\text { Voltage } \\
\text { Output } \\
(\mathrm{mV})\end{array}$ \\
\hline $\begin{array}{l}\mathrm{Li} \text { et al. } \\
(2008) \text { [29] }\end{array}$ & PVDF-TrFE & Dome & 0.5 & 25 & up to 10.6 & / & 0-1000 & $0-11$ \\
\hline $\begin{array}{l}\text { Kim et al. } \\
(2014) \text { [30] }\end{array}$ & PVDF & Dome & 0.9 & 15 & up to 8830 & / & $0-500$ & $0-5000$ \\
\hline $\begin{array}{l}\text { Dagdeviren } \\
\text { et al. (2014) } \\
\text { [39] }\end{array}$ & PZT & Flat & 0.25 & 2 & 11.6 & / & $2-10.5$ & $0.001-0.1$ \\
\hline $\begin{array}{l}\text { Lee et al. } \\
(2014) \text { [40] }\end{array}$ & $\mathrm{PZT}$ & Flat & 3 & 15.2 & 105 & / & 10-100 & $1-12$ \\
\hline $\begin{array}{l}\text { Khan et al. } \\
\text { (2015) [31] }\end{array}$ & $\begin{array}{l}\text { PVDF-TrFe } \\
+\mathrm{MWCN}\end{array}$ & Flat & / & 200 & 500 & / & $400-4000$ & $4-16$ \\
\hline $\begin{array}{l}\text { Maita et al. } \\
\text { (2014) [33] }\end{array}$ & AlN & Flat & / & 500 & 13 & / & 500-2000 & $3-10$ \\
\hline $\begin{array}{l}\text { Mastronardi } \\
\text { et al. (2014, } \\
2015) \\
{[27,82]}\end{array}$ & AlN & Dome & 0.75 & 1.2 & up to 480 & up to 950 & $0-60$ & $0-37$ \\
\hline
\end{tabular}

${ }^{\mathrm{a}}$ Res. $=$ Resolution

As shown in Table 2, the integration of domed structures made of aluminum nitride and flexible substrate is a strategy to have both dynamic and static detection of contact forces and pressures. By considering the surface area of a single DSDT, about $0.384 \mu \mathrm{m}^{2}$, it can be assessed that the AlN and polyimide-based sensors successfully detect pressure from the low-pressure regime $(1 \mathrm{kPa}-10 \mathrm{kPa}) \mathrm{up}$ to the medium-pressure regime $(10 \mathrm{kPa}-100 \mathrm{kPa})$, as illustrated in Figure 17. 

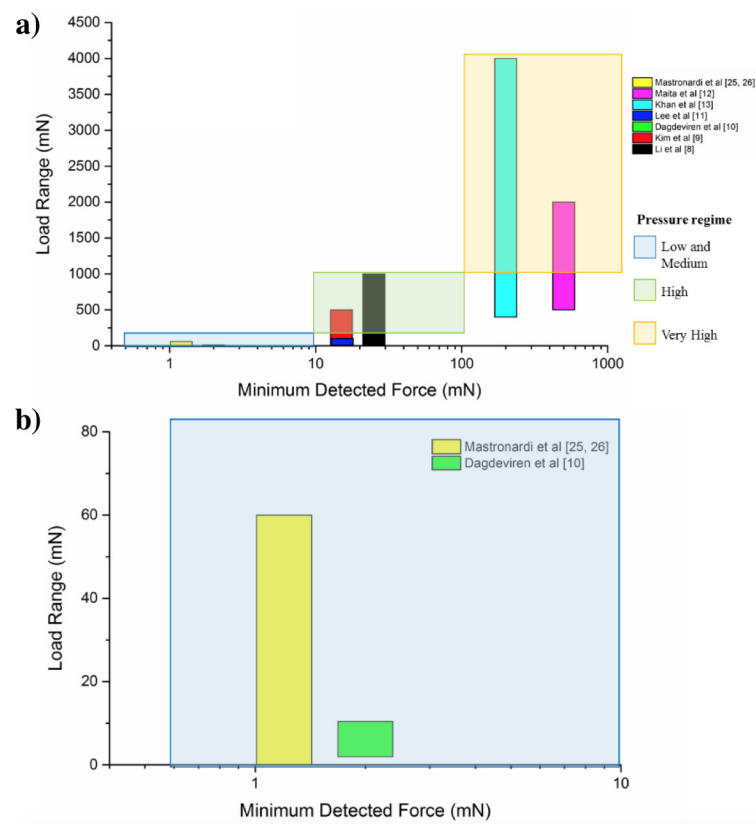

Figure 17. Pressure detection in the low and medium, high and very high pressure regime. (a) Mapping of the listed devices (Table 2) to their detectable load ranges; (b) magnification of the low and medium pressure regime.

Table 3. Comparison between pMUT made of AlN active thin-film.

\begin{tabular}{|c|c|c|c|c|c|c|}
\hline Authors & Material & Shape & $\begin{array}{l}\text { Radius } \\
(\mu \mathrm{m})\end{array}$ & $\begin{array}{l}\text { Resonance } \\
\text { Frequency } \\
\text { (kHz) }\end{array}$ & $\begin{array}{l}\text { Displacement } \\
(\mathrm{nm})\end{array}$ & $\begin{array}{l}\text { Driving } \\
\text { Voltage } \\
\text { (V) }\end{array}$ \\
\hline $\begin{array}{l}\text { Shelton et al. } \\
(2009) \text { [83] }\end{array}$ & $\mathrm{Si} / \mathrm{SiO}_{2} / \mathrm{AlN}$ & $\begin{array}{l}\text { Flat } \\
\text { circular }\end{array}$ & $175-225$ & 220 & $1000-1300$ & $0.5-7$ \\
\hline $\begin{array}{l}\text { Przybyla et al. } \\
(2010)[84]\end{array}$ & $\mathrm{Si} / \mathrm{SiO}_{2} / \mathrm{AlN}$ & $\begin{array}{l}\text { Flat } \\
\text { circular }\end{array}$ & 200 & 214 & $100-750$ & $0.5-15$ \\
\hline $\begin{array}{l}\text { Akhbari et al. } \\
\text { (2014) [77] }\end{array}$ & $\mathrm{Si} / \mathrm{AlN}$ & $\begin{array}{l}\text { Concave } \\
\text { curved } \\
\text { circular }\end{array}$ & 60-95 & 500-2190 & $0-5$ & $0-10$ \\
\hline $\begin{array}{l}\text { Guedes et al. } \\
(2011)[85]\end{array}$ & $\mathrm{Si} / \mathrm{SiO}_{2} / \mathrm{AlN}$ & $\begin{array}{l}\text { Flat } \\
\text { flexurally } \\
\text { suspended } \\
\text { circular }\end{array}$ & 200 & 121.3 & 0-1100 & $0-30$ \\
\hline $\begin{array}{l}\text { Mastronardi et al. } \\
(2014) \text { [28] }\end{array}$ & PI/AlN & $\begin{array}{l}\text { Dome } \\
\text { curved } \\
\text { circular }\end{array}$ & $250-300$ & $390-680$ & $0.5-8$ & 0-10 \\
\hline
\end{tabular}

Aluminum nitride was successfully used to develop and fabricate piezoelectric micromachined ultrasonic transducers. Akhbari et al. [43,77] demonstrated the effects of the residual stress in AlN on the dynamic responses of stress engineered curved pMUT devices. Especially, as the residual stress in the AlN increases, the low-frequency displacement per unit input voltage drops, and the resonant frequency increases. Table 3 gives a comparative overview of pMUTs based on AlN active thin film, which were patterned with different shapes and geometries, moving from standard flat membranes, to flexurally suspended circular elements, up to concave or dome-shaped curved cells. 
The performance of each device, that is resonance frequency, displacement range and corresponding driving voltage, is listed.

As reported by Mastronardi et al. [28], a pMUT consisting of flexible piezoelectric membranes of AlN (with a thickness of $800 \mathrm{~nm}$ ) is fabricated on $25 \mu \mathrm{m}$-thick Kapton flexible substrate by exploiting the same technology of tactile sensors and the inverse piezoelectric effect. The final transducers (shown in Figure 18a,b) have a radius of 250, 275 and $300 \mu \mathrm{m}$. They were assumed to behave like mechanically-clamped homogeneous plate resonators by virtue of the three-dimensional structures achieved after the release of the residual stress (estimated as $-48.1 \pm 0.5 \mathrm{MPa}$ [28]).

The mechanical behavior of the circular membranes was investigated by driving the piezoelectric film by means of a sinusoidal voltage whose frequency sweeps from $0.5 \mathrm{~Hz}-2 \mathrm{MHz}$, as presented in Figure 18c. In this frequency range, the different mode shapes at resonances have been clearly identified. A typical Gaussian-like shape can be seen by the 3D reconstruction of the out-of-plane deflection of the $(0,1)$ fundamental resonant mode (inset in Figure 18c), where the maximum displacement is achieved at the center of the membranes. A maximum displacement of about $8.0 \mathrm{~nm}$ has been measured by driving the membranes with a maximum voltage of $10 V_{p p}$ (see Figure $18 \mathrm{~d}$ ), even if the membranes are still attached to a rigid support. Moreover, the amplitude of the displacement increases linearly with the actuation voltage, and no deviation from the linearity has been observed up to the maximum limit voltage of $10 \mathrm{~V}_{\mathrm{pp}}$.
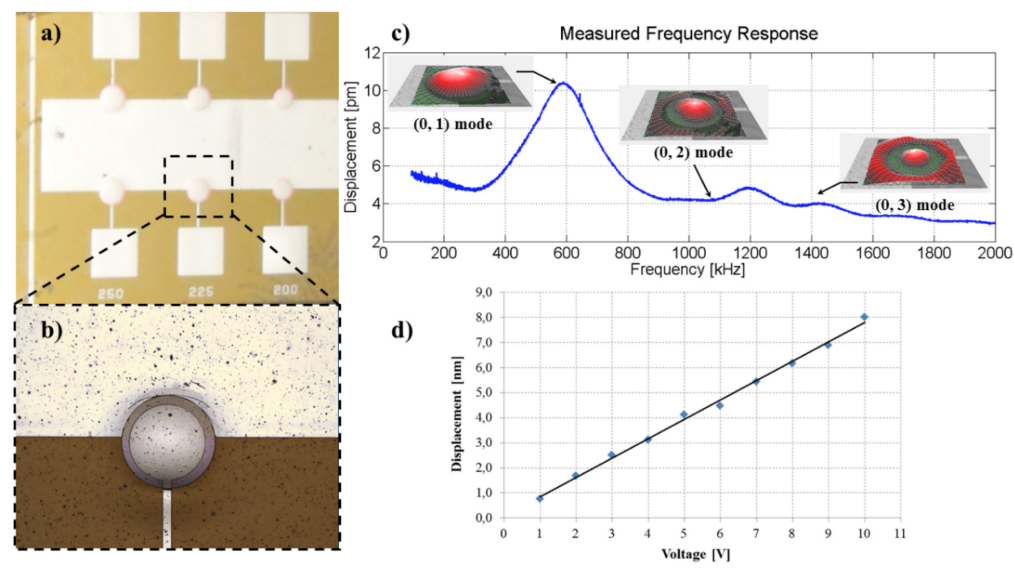

Figure 18. Mechanical behavior of the circular membranes of the final piezoelectric ultrasonic transducer. (a,b) Microscope pictures of the final piezoelectric ultrasonic transducer. (c) The mechanical behavior of the circular membranes has been investigated by driving the piezoelectric film by means of a sinusoidal voltage whose frequency sweeps from $0.5 \mathrm{~Hz}-2 \mathrm{MHz}$. Different mode shapes at resonances have been clearly identified. (d) The displacement amplitude increases linearly with actuation voltage. Reproduced from Mastronardi et al. [28] with permission of Elsevier B.V.

\section{Conclusions}

In this review, we described a stress-driven approach to design and fabricate flexible nitride-based MEMS devices for sensing applications. A controllable stress gradient along the cross-section of thin aluminum nitride and silicon nitride layers can be induced by appropriately designing and micromachining multilayered thin films. By depositing piezoresistive nichrome strain gauges onto nitride-based multilayers or by using direct piezoelectric properties of aluminum nitride-based microstructures, highly sensitive mechanical strain/stress detection can be realized, turning dome-shaped membranes and upwards-bent cantilevers into tactile and flow sensors for various fields of applications. Future development on stress-driven bio-inspired technology will be directed towards large area systems for robotics and ultrasonics applications. Next generation artificial hair cell-like flow sensors might not only approximate the morphological properties of biological neuromasts 
more precisely, but also bio-mimic physiological functions, such as bidirectional sensitivity and interconnections between individual hair cells. Dome-shaped devices could be designed as an array of sensors and ultrasonics generators for both dynamic and static tactile sensing based on contact and ultrasonic range finding. Future developments will be focused on the experimental evaluation of the contribution of flexoelectricity in a tactile stress-driven device as a function of the AlN material thickness, in order to better control flexoelectric properties.

Acknowledgments: Claudio Abels gratefully acknowledges the financial support offered by Rhine-Waal University of Applied Sciences.

Author Contributions: William M. Megill, Massimo De Vittorio and Francesco Rizzi developed the fundamental principles and theoretical background. Claudio Abels, Vincenzo Mariano Mastronardi, Francesco Guido and Tommaso Dattoma conceived, designed and performed the experiments and analyzed the data. Antonio Qualtieri contributed to reagents/materials/manufacturing/analysis tools. Claudio Abels, Vincenzo Mariano Mastronardi and Francesco Rizzi wrote the paper.

Conflicts of Interest: The authors declare no conflict of interest.

\section{Abbreviations}

The following abbreviations are used in this manuscript:

$\begin{array}{ll}\text { AlN } & \text { Aluminum Nitride } \\ \text { CCC } & \text { Cross-Correlation Coefficient } \\ \text { CCF } & \text { Cross-Correlation Function } \\ \text { CMOS } & \text { Complementary Metal-Oxide-Semiconductor } \\ \text { CMP } & \text { Chemical Mechanical Polishing } \\ \text { COC } & \text { Cyclic Olefin Copolymer } \\ \text { CVP } & \text { Chemical Vapor Deposition } \\ \mathrm{Cr} & \text { Chrome } \\ \text { DRIE } & \text { Deep Reactive Ion Etching } \\ \text { DSDT } & \text { Dome-Shaped Diaphragm Transducer } \\ \text { ICP } & \text { Inductively Coupled Plasma } \\ \text { KOH } & \text { Potassium Hydroxide } \\ \text { LPCVD } & \text { Low Pressure Chemical Vapor Deposition } \\ \text { LTO } & \text { Low Temperature Oxide } \\ \text { MEMS } & \text { Micro-Electro-Mechanical Systems } \\ \mathrm{Mo} & \text { Molybdenum } \\ \text { PECVD } & \text { Plasma-Enhanced Chemical Vapor Deposition } \\ \text { pMUT } & \text { Piezoelectric Micromachined Ultrasonic Transducers } \\ \text { PVDF } & \text { Polyvinylidene Difluoride } \\ \text { PZT } & \text { Lead Zirconate Titanate } \\ \text { RIE } & \text { Reactive Ion Etching } \\ \text { SF6 } & \text { Sulfur Hexafluoride } \\ \mathrm{Si} & \text { Silicon } \\ \mathrm{SiCl} & \text { Silicon Tetrachloride } \\ \mathrm{SiN} & \text { Silicon Nitride } \\ \mathrm{SiO}{ }_{2} & \text { Silicon Dioxide } \\ \mathrm{SOI} & \text { Silicon-On-Insulator } \\ \mathrm{TrFE} & \text { Trifluoroethylene } \\ \mathrm{UT} & \text { Ultrasonic Transducer } \\ \mathrm{VDF} & \text { Vinylidene Fluoride } \\ \mathrm{ZnO} & \text { Zinc Oxide } \\ & \end{array}$




\section{References}

1. Bao, M. Analysis and Design Principles of MEMS Devices; Elsevier: Amsterdam, The Netherlands, 2005.

2. Judy, J.W. Microelectromechanical systems (MEMS): Fabrication, design and applications. Smart Mater. Struct. 2001, 10, 1115-1134.

3. Liu, C. Foundations of MEMS, 2nd ed.; Pearson: Upper Saddle River, NJ, USA, 2012.

4. Cai, S.; Breid, D.; Crosby, A.; Suo, Z.; Hutchinson, J. Periodic patterns and energy states of buckled films on compliant substrates. J. Mech. Phys. Solids 2011, 59, 1094-1114.

5. Gioia, G.; Ortiz, M. Delamination of compressed thin films. Adv. Appl. Mech. 1997, 33, 119-192.

6. Freund, L.B.; Suresh, S. Thin Film Materials: Stress, Defect Formation and Surface Evolution; Cambridge University Press: Cambridge, UK, 2004.

7. Wang, Y.H.; Lee, C.Y.; Chiang, C.M. A MEMS-based Air Flow Sensor with a Free-standing Micro-cantilever Structure. Sensors 2007, 7, 2389-2401.

8. Kao, I.; Kumar, A.; Binder, J. Smart MEMS Flow Sensor: Theoretical Analysis and Experimental Characterization. IEEE Sens. J. 2007, 7, 713-722.

9. Zhang, Q.; Ruan, W.; Wang, H.; Zhou, Y.; Wang, Z.; Liu, L. A self-bended piezoresistive microcantilever flow sensor for low flow rate measurement. Sens. Actuators A 2010, 158, 273-279.

10. Rizzi, F.; Qualtieri, A.; Chambers, L.D.; Epifani, G.; Megill, W.M.; De Vittorio, M. Stress-Driven Artificial Hair Cell for Flow Sensing. In Flow Sensing in Air and Water: Behavioral, Neural and Engineering Principles of Operation; Bleckmann, H., Mogdans, J., Coombs, S.L., Eds.; Springer: Berlin, Germany, 2014; pp. 499-519.

11. Claassen, W.; Valkenburg, W.; Willemsen, M.; vd Wijgert, W. Influence of deposition temperature, gas pressure, gas phase composition, and RF frequency on composition and mechanical stress of plasma silicon nitride layers. J. Electrochem. Soc. 1985, 132, 893-898.

12. Franz, G. Low Pressure Plasmas and Microstructuring Technology; Springer: Berlin/Heidelberg, Germany, 2009.

13. Reif, R.; Kern, W. IV-1-Plasma-Enhanced Chemical Vapor Deposition. In Thin Film Processes; Vossen, J.L.; Kern, W., Eds.; Academic Press: San Diego, CA, USA, 1991; pp. 525-564.

14. Rizzi, F.; Qualtieri, A.; Chambers, L.D.; Megill, W.M.; de Vittorio, M. Parylene conformal coating encapsulation as a method for advanced tuning of mechanical properties of an artificial hair cell. Soft Matter 2013, 9, 2584-2588.

15. Wang, Y.H.; Hsueh, T.H.; Ma, R.H.; Lee, C.Y.; Fu, L.M.; Chou, P.C.; Tsai, C.H. A microcantilever-based gas flow sensor for flow rate and direction detection. In Proceedings of the 2008 Symposium on Design, Test, Integration and Packaging of MEMS/MOEMS, Nice, France, 9-11 April 2008; pp. 142-145.

16. Dubois, M.A.; Muralt, P. Stress and piezoelectric properties of aluminum nitride thin films deposited onto metal electrodes by pulsed direct current reactive sputtering. J. Appl. Phys. 2001, 89, 6389-6395.

17. Iborra, E.; Olivares, J.; Clement, M.; Vergara, L.; Sanz-Hervás, A.; Sangrador, J. Piezoelectric properties and residual stress of sputtered AlN thin films for \{MEMS\} applications. Sens. Actuators A 2004, 115, 501-507.

18. Giordano, C.; Ingrosso, I.; Todaro, M.; Maruccio, G.; Guido, S.D.; Cingolani, R.; Passaseo, A.; de Vittorio, M. AlN on polysilicon piezoelectric cantilevers for sensors/actuators. Microelectron. Eng. 2009, 86, 1204-1207.

19. Petroni, S.; Tegola, C.L.; Caretto, G.; Campa, A.; Passaseo, A.; De Vittorio, M.; Cingolani, R. Aluminum Nitride piezo-MEMS on polyimide flexible substrates. Microelectron. Eng. 2011, 88, 2372-2375.

20. Ababneh, A.; Alsumady, M.; Seidel, H.; Manzaneque, T.; Hernando-García, J.; Sánchez-Rojas, J.; Bittner, A.; Schmid, U. c-axis orientation and piezoelectric coefficients of AlN thin films sputter-deposited on titanium bottom electrodes. Appl. Surf. Sci. 2012, 259, 59-65.

21. Jin, H.; Zhou, J.; Dong, S.; Feng, B.; Luo, J.; Wang, D.; Milne, W.; Yang, C. Deposition of c-axis orientation aluminum nitride films on flexible polymer substrates by reactive direct-current magnetron sputtering. Thin Solid Films 2012, 520, 4863-4870.

22. Jackson, N. Influence of silicon crystal orientation on piezoelectric textured aluminium nitride deposited on metal electrodes. Vacuum 2016, 132, 47-52.

23. Jackson, N.; Mathewson, A. Enhancing the piezoelectric properties of flexible hybrid AlN materials using semi-crystalline parylene. Smart Mater. Struct. 2017, 26, 045005.

24. Jang, J.; Jang, J.H.; Choi, H. Piezoelectric ALN cantilever array on a SU-8 substrate for flexible artificial basilar membrane. In Proceedings of the 2017 IEEE 30th International Conference on Micro Electro Mechanical Systems (MEMS), Las Vegas, NV, USA, 22-26 February 2017; pp. 1200-1203. 
25. Andrei, A.; Krupa, K.; Jozwik, M.; Delobelle, P.; Hirsinger, L.; Gorecki, C.; Nieradko, L.; Meunier, C. AlN as an actuation material for $\{$ MEMS $\}$ applications: The case of AlN driven multilayered cantilevers. Sens. Actuators A 2008, 141, 565-576.

26. Qualtieri, A.; Rizzi, F.; Todaro, M.; Passaseo, A.; Cingolani, R.; De Vittorio, M. Stress-driven AlN cantilever-based flow sensor for fish lateral line system. Microelectron. Eng. 2011, 88, 2376-2378.

27. Mastronardi, V.M.; Ceseracciu, L.; Guido, F.; Rizzi, F.; Athanassiou, A.; De Vittorio, M.; Petroni, S. Low stiffness tactile transducers based on AlN thin film and polyimide. Appl. Phys. Lett. 2015, 106, 162901.

28. Mastronardi, V.M.; Guido, F.; Amato, M.; de Vittorio, M.; Petroni, S. Piezoelectric ultrasonic transducer based on flexible AlN. Microelectron. Eng. 2014, 121, 59-63.

29. Li, C.; Wu, P.M.; Lee, S.; Gorton, A.; Schulz, M.J.; Ahn, C.H. Flexible Dome and Bump Shape Piezoelectric Tactile Sensors Using PVDF-TrFE Copolymer. J. Microelectromech. Syst. 2008, 17, 334-341.

30. Kim, M.S.; Ahn, H.R.; Lee, S.; Kim, C.; Kim, Y.J. A dome-shaped piezoelectric tactile sensor arrays fabricated by an air inflation technique. Sens. Actuators A 2014, 212, 151-158.

31. Khan, S.; Tinku, S.; Lorenzelli, L.; Dahiya, R.S. Flexible Tactile Sensors Using Screen-Printed P(VDF-TrFE) and MWCNT/PDMS Composites. IEEE Sens. J. 2015, 15, 3146-3155.

32. Dahiya, R.S.; Valle, M.; Metta, G.; Lorenzelli, L.; Pedrotti, S. Deposition, processing and characterization of P (VDF-TrFE) thin films for sensing applications. In Proceedings of the 2008 on Sensors, Lecce, Italy, 26-29 October 2008; pp. 490-493.

33. Maita, F.; Maiolo, L.; Pecora, A.; Minotti, A.; Fortunato, G.; Smecca, E.; Alberti, A. Low-temperature flexible piezoelectric AIN capacitor integrated on ultra-flexible poly-Si TFT for advanced tactile sensing. In Proceedings of the Sensors, Valencia, Spain, 2-5 November 2014; pp. 1730-1733.

34. Jackson, N.; Keeney, L.; Mathewson, A. Flexible-CMOS and biocompatible piezoelectric AlN material for MEMS applications. Smart Mater. Struct. 2013, 22, 115033.

35. Ma, W. Flexoelectricity: strain gradient effects in ferroelectrics. Phys. Scr. 2007, 2007, 180-183.

36. Zubko, P.; Catalan, G.; Tagantsev, A.K. Flexoelectric Effect in Solids. Annu. Rev. Mater. Res. 2013, 43, $387-421$.

37. Zhou, Y.; Wang, Z.; Wang, C.; Ruan, W.; Liu, L. Design, fabrication and characterization of a two-step released silicon dioxide piezoresistive microcantilever immunosensor. J. Micromech. Microeng. 2009, 19, 065026.

38. Qualtieri, A.; Rizzi, F.; Epifani, G.; Ernits, A.; Kruusmaa, M.; De Vittorio, M. Parylene-coated bioinspired artificial hair cell for liquid flow sensing. Microelectron. Eng. 2012, 98, 516-519.

39. Dagdeviren, C.; Su, Y.; Joe, P.; Yona, R.; Liu, Y.; Kim, Y.S.; Huang, Y.; Damadoran, A.R.; Xia, J.; Martin, L.W.; et al. Conformable amplified lead zirconate titanate sensors with enhanced piezoelectric response for cutaneous pressure monitoring. Nat. Commun. 2014, 5, 4496.

40. Lee, J.; Choi, W.; Yoo, Y.K.; Hwang, K.S.; Lee, S.M.; Kang, S.; Kim, J.; Lee, J.H. A Micro-Fabricated Force Sensor Using an All Thin Film Piezoelectric Active Sensor. Sensors 2014, 14, 22199-22207.

41. Goericke, F.; Mansukhani, K.; Yamamoto, K.; Pisano, A. Experimentally validated aluminum nitride based pressure, temperature and 3-axis acceleration sensors integrated on a single chip. In Proceedings of the 2014 IEEE 27th International Conference on Micro Electro Mechanical Systems (MEMS), San Francisco, CA, USA, 26-30 January 2014; pp. 729-732.

42. Feng, G.H. A piezoelectric dome-shaped-diaphragm transducer for microgenerator applications. Smart Mater. Struct. 2007, 16, 2636-2644.

43. Akhbari, S.; Sammoura, F.; Yang, C.; Heidari, A.; Horsley, D.; Lin, L. Self-curved diaphragms by stress engineering for highly responsive pMUT. In Proceedings of the 28th IEEE International Conference on Micro Electro Mechanical Systems (MEMS), Estoril, Portugal, 18-22 January 2015; pp. 837-840.

44. Bleckmann, H.; Mogdans, J.; Coombs, S.L. (Eds.) Flow Sensing in Air and Water; Springer: Berlin, Germany, 2014.

45. Coombs, S.; Bleckmann, H.; Fay, R.; Popper, A. (Eds.) The Lateral Line System; Springer: New York, NY, USA, 2014.

46. McHenry, M.J.; Liao, J.C. The Hydrodynamics of Flow Stimuli. In The Lateral Line System; Coombs, S., Bleckmann, H., Fay, R.R., Popper, A.N., Eds.; Springer: New York, NY, USA, 2014; pp. 73-98.

47. Nawi, M.N.M.; Manaf, A.A.; Arshad, M.R.; Sidek, O. Review of MEMS flow sensors based on artificial hair cell sensor. Microsyst. Technol. 2011, 17, 1417-1426.

48. Tao, J.; Yu, X.B. Hair flow sensors: From bio-inspiration to bio-mimicking-A review. Smart Mater. Struct. 2012, 21, 113001. 
49. Shizhe, T. Underwater artificial lateral line flow sensors. Microsyst. Technol. 2014, 20, 2123-2136.

50. Rizzi, F.; Qualtieri, A.; Dattoma, T.; Epifani, G.; De Vittorio, M. Biomimetics of underwater hair cell sensing. Microelectron. Eng. 2015, 132, 90-97.

51. Liu, G.; Wang, A.; Wang, X.; Liu, P. A Review of Artificial Lateral Line in Sensor Fabrication and Bionic Applications for Robot Fish. Appl. Bionics Biomech. 2016, 2016, 4732703.

52. Yilmazoglu, O.; Yadav, S.; Cicek, D.; Schneider, J.J. A nano-microstructured artificial-hair-cell-type sensor based on topologically graded 3D carbon nanotube bundles. Nanotechnology 2016, 27, 365502.

53. Ozaki, Y.; Ohyama, T.; Yasuda, T.; Shimoyama, I. An air flow sensor modeled on wind receptor hairs of insects. In Proceedings of the IEEE Thirteenth Annual International Conference on Micro Electro Mechanical Systems (Cat. No.00CH36308), Miyazaki, Japan, 27 January 2000; pp. 531-536.

54. Fan, Z.; Chen, J.; Zou, J.; Bullen, D.; Liu, C.; Delcomyn, F. Design and fabrication of artificial lateral line flow sensors. J. Micromech. Microeng. 2002, 12, 655-661.

55. Chen, J.; Fan, Z.; Zou, J.; Engel, J.; Liu, C. Two-Dimensional Micromachined Flow Sensor Array for Fluid Mechanics Studies. J. Aerosp. Eng. 2003, 16, 85-97.

56. Engel, J.M.; Chen, J.; Bullen, D.; Liu, C. Polyurethane rubber as a MEMS material: characterization and demonstration of an all-polymer two-axis artificial hair cell flow sensor. In Proceedings of the 18th IEEE International Conference on Micro Electro Mechanical Systems, Miami Beach, FL, USA, 30 January-3 February 2005; pp. 279-282.

57. Tucker, C.; Chen, N.; Engel, J.; Yang, Y.; Pandya, S.; Liu, C. High-Sensitivity Bi-Directional Flow Sensor Based on Biological Inspiration of Animal Haircell Sensors. In Proceedings of the 5th IEEE Conference on Sensors, Daegu, Korea, 22-25 October 2006; pp. 1440-1442.

58. Chen, N.; Tucker, C.; Engel, J.M.; Yang, Y.; Pandya, S.; Liu, C. Design and Characterization of Artificial Haircell Sensor for Flow Sensing With Ultrahigh Velocity and Angular Sensitivity. J. Microelectromech. Syst. 2007, 16, 999-1014.

59. Peleshanko, S.; Julian, M.; Ornatska, M.; McConney, M.; LeMieux, M.; Chen, N.; Tucker, C.; Yang, Y.; Liu, C.; Humphrey, J.; et al. Hydrogel-Encapsulated Microfabricated Haircells Mimicking Fish Cupula Neuromast. Adv. Mater. 2007, 19, 2903-2909.

60. Aiyar, A.R.; Song, C.; Kim, S.H.; Allen, M.G. An all-polymer airflow sensor using a piezoresistive composite elastomer. Smart Mater. Struct. 2009, 18, 115002.

61. Du, L.; Zhao, Z.; Pang, C.; Fang, Z.; Liu, Y.; Han, Y. Micro solid state silicon plate wind velocity sensor. In Proceedings of the 4th IEEE International Conference on Nano/Micro Engineered and Molecular Systems, Shenzhen, China, 5-8 January 2009; pp. 1-4.

62. Du, L.; Zhao, Z.; Pang, C.; Fang, Z. Drag force micro solid state silicon plate wind velocity sensor. Sens. Actuators A 2009, 151,35-41.

63. McConney, M.E.; Chen, N.; Lu, D.; Hu, H.A.; Coombs, S.; Liu, C.; Tsukruk, V.V. Biologically inspired design of hydrogel-capped hair sensors for enhanced underwater flow detection. Soft Matter 2009, 5, 292-295.

64. Song, C.; Aiyar, A.R.; Kim, S.H.; Allen, M.G. Exploitation of aeroelastic effects for drift reduction in an all-polymer air flow sensor. Sens. Actuators A 2009, 165, 66-72.

65. Klein, A.; Bleckmann, H. Determination of object position, vortex shedding frequency and flow velocity using artificial lateral line canals. Beilstein J. Nanotechnol. 2011, 2, 276-283.

66. Herzog, H.; Steltenkamp, S.; Klein, A.; Tätzner, S.; Schulze, E.; Bleckmann, H. Micro-Machined Flow Sensors Mimicking Lateral Line Canal Neuromasts. Micromachines 2015, 6, 1189-1212.

67. Herzog, H.; Klein, A.; Bleckmann, H.; Holik, P.; Schmitz, S.; Siebke, G.; Tatzner, S.; Lacher, M.; Steltenkamp, S. mu-Biomimetic flow-sensors-introducing light-guiding PDMS structures into MEMS. Bioinspiration Biomim. 2015, 10, 036001.

68. Abels, C.; Qualtieri, A.; De Vittorio, M.; Megill, W.M.; Rizzi, F. A bio-inspired real-time capable artificial lateral line system for freestream flow measurements. Bioinspiration Biomim. 2016, 11, 035006.

69. Dahiya, R.S.; Metta, G.; Valle, M.; Sandini, G. Tactile Sensing-From Humans to Humanoids. IEEE Trans. Robot. 2010, 26, 1-20.

70. Lee, W.W.; Cabibihan, J.; Thakor, N.V. Bio-mimetic strategies for tactile sensing. In Proceedings of the 2013 IEEE SENSORS, Baltimore, MD, USA, 3-6 November 2013; pp. 1-4.

71. Lederman, S.J.; Browse, R.A. The Physiology and Psychophysics of Touch. In Sensors and Sensory Systems for Advanced Robots; Dario, P., Ed.; Springer: Berlin/Heidelberg, Germany, 1988; Volume 43, pp. 71-91. 
72. Sadava, D.; Hillis, D.; Heller, H. Life: The Science of Biology; Sinauer Associates: Sunderland, MA, USA, 2011.

73. Kandel, E.R.; Schwartz, J.H.; Jessell, T.M.; Siegelbaum, S.A.; Hudspeth, A.J. (Eds.) Principles of Neural Science, 5th ed.; McGraw-Hill Companies: New York, NY, USA, 2013.

74. Vallbo, A.B.; Johansson, R.S. Properties of cutaneous mechanoreceptors in the human hand related to touch sensation. Hum Neurobiol. 1984, 3, 3-14.

75. Dahiya, R.; Valle, M. Tactile Sensing Technologies. In Robotic Tactile Sensing; Springer: Dordrecht, The Netherlands, 2013; pp. 79-136.

76. Amato, M.; Massimo De, V.; Petroni, S. Advanced MEMS Technologies for Tactile Sensing and Actuation. In MEMS, Devices, Circuits, and Systems; CRC Press: Boca Raton, FL, USA, 2013; pp. 351-380.

77. Akhbari, S.; Sammoura, F.; Shelton, S.; Yang, C.; Horsley, D.; Lin, L. Highly responsive curved aluminum nitride pMUT. In Proceedings of the 2014 IEEE 27th International Conference on Micro Electro Mechanical Systems (MEMS), San Francisco, CA, USA, 26-30 January 2014; pp. 124-127.

78. Lu, Y.; Horsley, D.A. Modeling, Fabrication, and Characterization of Piezoelectric Micromachined Ultrasonic Transducer Arrays Based on Cavity SOI Wafers. J. Microelectromech. Syst. 2015, 24, 1142-1149.

79. Lu, Y.; Tang, H.Y.; Fung, S.; Boser, B.E.; Horsley, D.A. Pulse-Echo Ultrasound Imaging Using an AlN Piezoelectric Micromachined Ultrasonic Transducer Array With Transmit Beam-Forming. J. Microelectromech. Syst. 2016, 25, 179-187.

80. Rozen, O.; Block, S.T.; Shelton, S.E.; Przybyla, R.J.; Horsley, D.A. Air-coupled aluminum nitride piezoelectric micromachined ultrasonic transducers at $0.3 \mathrm{MHz}$ to $0.9 \mathrm{MHz}$. In Proceedings of the 28th IEEE International Conference on Micro Electro Mechanical Systems (MEMS), Estoril, Portugal, 18-22 January 2015; pp. 921-924.

81. Guido, F.; Mastronardi, V.M.; Todaro, M.T.; Petroni, S.; De Vittorio, M. Piezoelectric soft MEMS for tactile sensing and energy harvesting. In Proceedings of the 2014 IEEE International Conference on IC Design Technology, Austin, TX, USA, 28-30 May 2014; pp. 1-4.

82. Mastronardi, V.M.; Guido, F.; de Vittorio, M.; Petroni, S. Flexible Force Sensor Based on C-axis Oriented Aluminum Nitride. Procedia Eng. 2014, 87, 164-167.

83. Shelton, S.; Chan, M.L.; Park, H.; Horsley, D.; Boser, B.; Izyumin, I.; Przybyla, R.; Frey, T.; Judy, M.; Nunan, K.; et al. CMOS-compatible AlN piezoelectric micromachined ultrasonic transducers. In Proceedings of the 2009 IEEE International Ultrasonics Symposium, Rome, Italy, 20-23 September 2009; pp. 402-405.

84. Przybyla, R.; Izyumin, I.; Kline, M.; Boser, B.; Shelton, S.; Guedes, A.; Horsley, D. An ultrasonic rangefinder based on an AlN piezoelectric micromachined ultrasound transducer. In Proceedings of the 2010 IEEE Sensors, Kona, HI, USA, 1-4 November 2010; pp. 2417-2421.

85. Guedes, A.; Shelton, S.; Przybyla, R.; Izyumin, I.; Boser, B.; Horsley, D.A. Aluminum nitride pMUT based on a flexurally-suspended membrane. In Proceedings of the 16th International Solid-State Sensors, Actuators and Microsystems Conference, Beijing, China, 5-9 June 2011; pp. 2062-2065.

(C) 2017 by the authors. Licensee MDPI, Basel, Switzerland. This article is an open access article distributed under the terms and conditions of the Creative Commons Attribution (CC BY) license (http://creativecommons.org/licenses/by/4.0/). 